NBER WORKING PAPER SERIES

\title{
SEARCH-THEORETIC MODELS OF THE LABOR MARKET:
}

A SURVEY

\author{
Richard Rogerson \\ Robert Shimer \\ Randall Wright
}

Working Paper 10655

http://www.nber.org/papers/w10655

\author{
NATIONAL BUREAU OF ECONOMIC RESEARCH \\ 1050 Massachusetts Avenue \\ Cambridge, MA 02138
}

August 2004

The views expressed herein are those of the author(s) and not necessarily those of the National Bureau of Economic Research.

(C)2004 by Richard Rogerson, Robert Shimer, and Randall Wright. All rights reserved. Short sections of text, not to exceed two paragraphs, may be quoted without explicit permission provided that full credit, including (C) notice, is given to the source. 
Search-Theoretic Models of the Labor Market: A Survey

Richard Rogerson, Robert Shimer, and Randall Wright

NBER Working Paper No. 10655

August 2004

JEL No. E2, J6

\section{ABSTRACT}

We survey search-theoretic models of the labor market and discuss their usefulness for analyzing labor market dynamics, job turnover, and wages. We first examine single-agent models, showing how they can incorporate many interesting features and generate rich predictions. We then consider equilibrium models that endogenize several variables that are treated parametrically in single-agent models, including the arrival rate of job offers and the wage distribution. We survey alternative formulations of these models, emphasizing two key issues: how workers and firms meet, and how wages are determined. We emphasize throughout the implications of alternative assumptions for turnover, wage dispersion, and efficiency.

Richard Rogerson

Departement of Economics

WP Carey School of Business

Arizona State University

Tempe, AZ 85287

and NBER

richard.rogerson@asu.edu

Robert Shimer

Department of Economics

University of Chicago

1126 East $59^{\text {th }}$ Street

Chicago, IL 60637

and NBER

shimer@uchicago.edu

Randall Wright

Department of Economics

University of Pennsylvania

3718 Locust Walk

Philadelphia, PA 19104

and NBER

rwright@econ.sas.upenn.edu 


\title{
Search-Theoretic Models of the Labor Market: A Survey*
}

\author{
Richard Rogerson Robert Shimer Randall Wright
}

July 9,2004

\section{Introduction}

The economic fortunes of most individuals are largely determined by their labor market experiences. Hence, economists are naturally interested not only in documenting and analyzing the empirical behavior of wages and employment, but also in building models within which we can study labor market outcomes from both a positive and a normative perspective, and within which we can assess the consequences of changes in labor market policies, regulations and institutions. While the usual paradigm of supply and demand in a frictionless labor market is useful for discussing some of the questions, important phenomena not easily addressed in this setup include labor market transitions, such as movements between employment and unemployment, and the distribution of wages across individuals and over time.

Since its inception search theory has been extremely useful for thinking about these things, and for addressing a host of related empirical and policy issues. Even the earliest models that study a single agent in isolation enhance our understanding and our ability to organize observations about the work histories of individuals. But more recently, equilibrium search theory has embedded these agents into models that endogenously determine important

${ }^{*}$ Rogerson: Arizona State University. Shimer: University of Chicago. Wright: University of Pennsylvania. We would like to thank Daron Acemoglu, Ken Burdett, Gwen Eudey, Derek Laing, John McMillan, Dale Mortensen and Peter Rupert for their input. We also thank the Federal Reserve Bank of Cleveland, ERMES at Paris 2, the National Science Foundation, and the Sloan Foundation for research support. 
variables like job creation and destruction rates and the wage distribution. The goal of this survey is to summarize these efforts, and in the process to provide a unifying perspective within which the various models can be seen. Throughout the presentation we will emphasize three things that search theory helps us understand: job creation, job destruction, and wages.

The kinds of questions that we will be concerned with include the following. What economic factors determine labor market transitions, and in particular what determines the equilibrium unemployment rate? Why do unemployed agents sometimes choose to remain unemployed, say by turning down offers, and more generally what determines the length of unemployment spells? How can ostensibly homogeneous workers end up with different wages? What are the trade-offs faced by firms when they pay different wages? What are the interactions between wages and turnover? And what determines the efficient amount of turnover? This essay shows that search theory provides a rigorous yet tractable framework that can be used to address these questions, and thereby provides important insights into the functioning of modern labor markets.

At the outset, it is important to point out that search theory constitutes a very large branch of economics. In addition to labor it has been used in many applications in both micro and macro, including monetary theory, industrial organization, finance, and the economics of the marriage market, all of which we must neglect lest this survey becomes unmanageable. ${ }^{1}$ Search has been used in technical theoretical work, and has been a workhorse for empirical economics, but we can neither delve into pure theory nor pay appropriate attention to all of the econometric issues or empirical results here. ${ }^{2}$ Also, while the analysis will strive to be rigorous, we want to emphasize applications and issues - that is, what can we learn about labor economics from these models - and not models or methods per se. Hence the presentation will revolve around the ways in which the models help us think about

\footnotetext{
${ }^{1}$ Examples in monetary economics include Kiyotaki-Wright (1993), Shi (1995) and Trejos-Wright (1995); examples in the marriage literature include Mortensen (1988), Burdett-Coles (1997, 1999) and Shimer-Smith (2000); examples in IO include Salop (1977), Jovanovic (1982), Jovanovic-MacDonald (1994), and Jovanovic-Rob (1989); examples in finance include Duffie-Garleanu-Pedersen (2002) and Weill (2003).

${ }^{2}$ Examples of theoretical work studying the question of whether frictionless competitive equilibrium can be considered the limit of search equilibrium as the frictions get small include Rubinstein-Wolinsky (1987), Gale (1987) and Mortensen-Wright (2002). DevineKiefer (1991) and Wolpin (1995) provide surveys of empirical applications.
} 
substantive issues related to turnover and wages.

The essay proceeds as follows. In Sections 2 and 3 we study the problem of a single agent, not only because this is the way the literature began but because it is an important component of the equilibrium models that follow. In Section 4 we consider models that build upon two main ingredients: the matching function, which determines how workers and firms get together, and the bargaining solution, which determines the wage once they do. In Section 5 we study a class of models where wages are posted ex ante, rather than bargained after workers and firms meet, and where agents use directed rather than random search. In Section 6 we discuss models with nontransferable utility, where the focus is on determining which matches get consummated. In Section 7 we present models where wages are posted ex ante but search is once again random, with an emphasis on wage dispersion. In Section 8 we discusses efficiency.

Although the different versions of the model that we present sometimes adopt some very different assumptions - e.g. random versus directed search, transferrable versus nontransferable utility, bargaining versus wage posting, and so on -we want to emphasize that they are really different applications of the same framework, and in each case the analysis uses the same set of basic tools. Our goal is that, with a little work, the reader should feel at the end of this article that search theory is a flexible and broadly applicable paradigm for organizing our thinking about labor markets, and that this will stimulate even more learning and research in the area. ${ }^{3}$

\section{A Simple Model}

We begin with the problem of an individual searching for a job in real time, taking market conditions as given. ${ }^{4}$ He seeks to maximize $\mathbb{E} \sum_{t=0}^{\infty} \beta^{t} x_{t}$, where

\footnotetext{
${ }^{3}$ Earlier surveys include Lippman-McCall (1976a), Mortensen (1986) and MortensenPissarides $(1999 a, b)$. Naturally there is some overlap with the current essay, although our approach and many of the issues we address are different. Examples of things emphsized here and not in those papers include the directed search models in Section 5, the nontransferable utility models in Section 6, some of the wage dispersion models in Section 7, and aspects of our approach to efficiency in Section 8.

${ }^{4}$ While it is often said that the economics of search began with Stigler (1961), his formulation was not really dynamic. McCall (1970), Mortensen (1970) and Gronau (1971) presented the first sequential models of job search, although others had posed related problems (including Simon 1955, who discussed looking for a house).
} 
$\beta \in(0,1)$ is the discount factor, $x_{t}$ is income at $t$, and $\mathbb{E}$ denotes the expectation. Income is $x=w$ if employed at wage $w$ and $x=b$ if unemployed. Although we refer to $w$ as the wage, more generally it could capture some measure of the desirability of the job, depending on things like benefits, location, prestige, etc. (see Hwang-Mortensen-Reed 1998). Similarly, although we will refer to $b>0$ as unemployment insurance (UI), it can also include the value of leisure or home production. ${ }^{5}$

The individual chooses a policy for whether to accept a job. We begin with the case where an unemployed individual samples one i.i.d. offer each period from a known distribution with CDF $F(w)$. If an offer is rejected the agent remains unemployed that period. Previously rejected offers cannot be recalled, although this assumption is not restrictive because the problem is stationary, so that an offer that is not acceptable today will not be acceptable tomorrow. For now we assume that if a job is accepted the worker keeps it forever. Hence, $W(w)=w /(1-\beta)$ is the payoff to accepting ( $W$ stands for the value of working). Similarly, $U=b+\beta \mathbb{E} \max \left\{W\left(w^{\prime}\right), U\right\}$, where the expectation is with respect to the next offer $w^{\prime}$, is the payoff from rejecting, earning $b$, waiting and sampling again ( $U$ stands for the value of unemployment).

Let the value of having an offer $w$ in hand be

$$
O(w)=\max \{W(w), U\}=\max \left\{\frac{w}{1-\beta}, b+\beta \mathbb{E} O\left(w^{\prime}\right)\right\} .
$$

Since $W(w)$ is increasing, there is a unique $w_{R}$ called the reservation wage such that $W\left(w_{R}\right)=U$, with the property that the agent should reject $w<w_{R}$ and accept $w>w_{R}$. Clearly, $w_{R}=(1-\beta) b+(1-\beta) \beta \mathbb{E} O\left(w^{\prime}\right)$, which expresses $w_{R}$ in terms of the unknown function $O$. To eliminate $O$, insert $b+\beta \mathbb{E} O\left(w^{\prime}\right)=$ $w_{R} /(1-\beta)$ into $(1)$ and integrate to get $\mathbb{E} O\left(w^{\prime}\right)=\mathbb{E} \max \left\{w^{\prime}, w_{R}\right\} /(1-\beta)$; then we have

$$
w_{R}=T\left(w_{R}\right) \equiv(1-\beta) b+\beta \int_{0}^{\infty} \max \left\{w, w_{R}\right\} d F(w) .
$$

\footnotetext{
${ }^{5}$ We formulate the problem as though the agent is interested in maximizing expected discounted income. This is the same as maximizing expected utility if the worker is risk neutral, of course, but also if he is risk averse and markets are complete, since then he can maximize utility by first maximizing income and then smoothing consumption. The case of a risk averse agent facing incomplete markets is more difficult. Early analyses include Danforth (1979) and Hall-Lippman-McCall (1979); more recent studies include Valdivia (1997), Costain (1997), Browning-Crossley-Smith (1999) and Lenz-Tranaes (2003).
} 
The function $T$ is easily shown to be a contraction. Hence, there is a unique solution to $w_{R}=T\left(w_{R}\right)$, and the sequence $w_{N+1}=T\left(w_{N}\right)$ converges to $w_{R}$ as $N \rightarrow \infty$ starting from any initial value of $w_{0}{ }^{6}$

Once we know $w_{R}$ we know everything there is to know about the optimal strategy. However, we also present some alternative representations often seen in the literature. First, subtracting $\beta w_{R}$ from both sides of (2) and simplifying, we get the usual reservation wage equation

$$
w_{R}=b+\frac{\beta}{1-\beta} \int_{w_{R}}^{\infty}\left(w-w_{R}\right) d F(w),
$$

which equates the utility per period from accepting $w_{R}$ to the payoff from rejecting, which is $b$ plus the expected improvement next period. Using integration by parts, we can also write

$$
w_{R}=b+\frac{\beta}{1-\beta} \int_{w_{R}}^{\infty}[1-F(w)] d w,
$$

which is quite handy in some of the applications below. ${ }^{7}$

A unifying theme of our essay is that search theory allows us to discuss issues neglected by traditional (supply and demand) theories of labor markets. Even this extremely basic model can be used to illustrate the point. The probability the worker gets a job each period, called the hazard rate, is $H=1-F\left(w_{R}\right)$, so the probability of being unemployed $t$ periods is $(1-H)^{t-1} H$ and the average duration of unemployment is

$$
D=\sum_{t=1}^{\infty} t(1-H)^{t-1} H=\frac{1}{H}
$$

Also, the observed distribution of wages paid is $G(w)=F\left(w \mid w \geq w_{R}\right)$.

Consider the impact of an increase in $b$ - say, more generous UI - which is an experiment we will come back to repeatedly. From the reservation wage equation the immediate effect is to increase $w_{R}$, which has two secondary

\footnotetext{
${ }^{6}$ Here $w_{N}$ can be interpreted as the reservation wage from a finite-horizon search problem with $N$ periods remaining, if we start at $w_{0}=b$, since $b$ is the reservation wage for a one-shot problem. One can check that $w_{N}$ converges monotonically to $w_{R}$; i.e. the finite-horizon reservation wage increases as the horizon gets longer.

${ }^{7}$ To derive (4), note that for any distribution with upper bound $\bar{w}, \int_{w_{R}}^{\bar{w}}\left(w-w_{R}\right) d F(w)=$ $\bar{w}-w_{R}-\int_{w_{R}}^{\bar{w}} F(w) d w=\int_{w_{R}}^{\bar{w}}[1-F(w)] d w$.
} 
effects: the distribution of observed wages $G(w)$ is higher in the sense of first order stochastic dominance, since more low wage offers are rejected; and the hazard rate $H$ is lower, increasing average unemployment duration. We will extend things in many ways in what follows, but this simple example shows how search-based models are well designed for discussing unemployment and wages. ${ }^{8}$

\section{Extensions}

Although the above model permits a rudimentary discussion of unemployment duration and the wage distribution, it is inadequate along several dimensions. For example, since workers receive 1 offer per period, a change $b$ affects things only through the reservation wage and not the offer arrival rate. Also it does not allow us to discuss the duration of employment, since by assumption jobs last forever. Here we consider some extensions to remedy this. These extensions, including search intensity, on-the-job search, wage changes and learning, are important ingredients into equilibrium models of the type discussed in later sections.

\subsection{Search Intensity}

As a first step, consider a worker who receives $n$ offers per period where $n$ is a Poisson random variable with parameter $\alpha$; i.e. the probability of $n \in\{0,1,2, \ldots\}$ is $\alpha^{n} e^{-\alpha} / n$ !. If a worker receives multiple offers, he either accepts the best, which is a random variable with $\operatorname{CDF} F(w)^{n}$, or rejects them all and continues searching. The logic used to derive (3) now implies

$$
w_{R}=b+\frac{\beta}{1-\beta} \sum_{n=1}^{\infty} \frac{\alpha^{n} e^{-\alpha}}{n !} \int_{w_{R}}^{\infty}\left(w-w_{R}\right) d F(w)^{n} .
$$

\footnotetext{
${ }^{8}$ Other results from this model that are not easy to discuss using supply and demand include the effects of changes in $F$. For some of these experiments it is useful to assume $F$ is $\log$-concave (i.e. $\log F$ is concave), which as first pointed out by Burdett (1981) is often useful in search theory. As an example, suppose we increase wages, in the sense of increasing every $w$ in the support of $F$ either by a constant or proportionally. Then perhaps surprisingly, one can show that $E\left[w \mid w \geq w_{R}\right]$ may go down, but it can be guaranteed to go up under log-concavity (Wright-Loberg 1987 show this under the interpretation that the changes in $w$ are due to tax changes).
} 
For some applications it is useful to consider the case where the length of a time period is very short. Thus, let $\Delta$ denote the period length and write $\beta=\frac{1}{1+r \Delta}$. The number of offers per period is now Poisson with parameter $\alpha \Delta$, and (6) becomes

$$
w_{R}=b+\frac{1}{r \Delta} \sum_{n=1}^{\infty} \frac{(\alpha \Delta)^{n} e^{-\alpha \Delta}}{n !} \int_{w_{R}}^{\infty}\left(w-w_{R}\right) d F(w)^{n} .
$$

Taking the limit as $\Delta \rightarrow 0$ gives

$$
w_{R}=b+\frac{\alpha}{r} \int_{w_{R}}^{\infty}\left(w-w_{R}\right) d F(w),
$$

since all terms in the summation except the first are of order $\Delta^{2}$, and hence become negligible when $\Delta$ is small. This is the continuous-time version of reservation wage equation (3); the continuous-time version of (4) follows from again integrating by parts. ${ }^{9}$

We now allow workers to choose their search intensity, making $\alpha$ endogenous. Assume that the (utility) cost of achieving arrival rate $\alpha$ is $g(\alpha)$, where $g^{\prime}>0$ and $g^{\prime \prime}>0$. Unemployed workers choose $\alpha$ to maximize the value of unemployed search, $r U=w_{R}$, where now

$$
w_{R}=b-g(\alpha)+\frac{\alpha}{r} \int_{w_{R}}^{\infty}\left(w-w_{R}\right) d F(w) .
$$

The first order condition for $\alpha$ (assuming an interior solution, which we can always guarantee with standard curvature conditions) is

$$
\int_{w_{R}}^{\infty}\left(w-w_{R}\right) d F(w)=r g^{\prime}(\alpha) .
$$

From (9) and (10), an increase in $b$ raises $w_{R}$ and reduces $\alpha$. Thus endogenous intensity introduces a new channel through which things like $b$ influence the outcome. Notice that here the hazard is $H=\alpha\left[1-F\left(w_{R}\right)\right]$, and the probability of finding a job after an unemployment spell of length $t$ is $H e^{-H t}$. Hence, the average duration of unemployment is $D=\int_{0}^{\infty} t H e^{-H t} d t=1 / H$, the same as $(5) \cdot{ }^{10}$

\footnotetext{
${ }^{9}$ When $\Delta$ is small, the time until the arrival of the next offer is an exponential random variable $t$ with distribution $1-e^{-\alpha t}$. This implies the expected time until the next offer is $1 / \alpha$, independent of history. We say this arrival process is memoryless.

${ }^{10}$ As a exercise, one can show $\partial H / \partial \alpha>0$ if $F$ is log-concave, but not in general (see Flinn-Heckman 1983 or Burdett-Ondrich 1985).
} 


\subsection{Turnover}

So far we have assumed that once an offer is accepted it is permanent. Sadly, perhaps, not all relationships last forever, so here we add the possibility that jobs end. Returning to the case of exogenous search intensity for now, suppose layoffs arrive according to a Poisson process with parameter $\lambda$. We endogenize this in various ways below, but for now $\lambda$ is constant. ${ }^{11}$ Also, because it will be useful for some applications, we introduce the possibility that the individual may die or otherwise permanently exit the market according to an independent Poisson process with parameter $\delta$, after which he gets utility normalized to 0 .

Let the period length be $\Delta$, the discount factor $\frac{1}{1+r \Delta}$, the probability of an offer $\alpha \Delta$, the probability of a layoff $\lambda \Delta$, and the probability of death $\delta \Delta$ per period (we implicitly ignore the possibility of multiple events within a period, and assume that $\Delta$ is sufficiently short so that all these probabilities are less than 1). Bellman's equations are

$$
\begin{aligned}
U & =b \Delta+\frac{1-\delta \Delta}{1+r \Delta}\left[\alpha \Delta \int_{0}^{\infty} \max \{W(w), U\} d F(w)+(1-\alpha \Delta) U\right] \\
W(w) & =w \Delta+\frac{1-\delta \Delta}{1+r \Delta}[\lambda \Delta U+(1-\lambda \Delta) W(w)] .
\end{aligned}
$$

Taking limits as $\Delta \rightarrow 0$ gives

$$
\begin{aligned}
(r+\delta) U & =b+\alpha \int_{0}^{\infty} \max \{W(w)-U, 0\} d F(w) \\
(r+\delta) W(w) & =w+\lambda[U-W(w)] .
\end{aligned}
$$

Again, the reservation wage satisfies $W\left(w_{R}\right)=U$, and the methods leading to (4) now yield

$$
w_{R}=b+\frac{\alpha}{r+\delta+\lambda} \int_{w_{R}}^{\infty}[1-F(w)] d w .
$$

Notice $\lambda$ and $\delta$ affect $w_{R}$ only by changing the effective discount rate to $r+\lambda+\delta$, but they also affect labor market transitions directly. Thus, the worker now goes through repeated spells of employment and unemployment,

\footnotetext{
${ }^{11}$ It is also interesting to let $\lambda$ vary across jobs, since then a reservation strategy needs to be defined in terms of the pair $(w, \lambda)$ (Burdett-Mortensen 1980; Wright 1987).
} 
and if he starts unemployed, on average he spends a fraction $(\lambda+\delta) /(H+\lambda+\delta)$ of his life unemployed. The model can be used for organizing micro data on individual wage and employment histories. But although it generates turnover, this model does so only through exogenous events like layoffs and deaths. We next consider extensions that endogenize job separations.

\subsubsection{On-the-job Search}

In reality much turnover is accounted for by job-to-job transitions with no intervening period of unemployment. The on-the-job search model of Burdett (1978) allows for this, and in addition explains how tenure at a particular job is correlated with other variables, such as the wage and quit rate. Following the presentation in Mortensen and Neumann (1984), suppose new offers arrive in continuous time at rate $\alpha_{0}$ while unemployed and $\alpha_{1}$ while employed. Each offer is a random draw from the same $F$. For now, search intensity and hence $\alpha_{0}$ and $\alpha_{1}$ are exogenous. Also, to reduce notation, for the rest of this section we set $\delta=0$. The strategy of an employed worker is obvious: accept any offer greater than your current wage. What needs to be determined is the strategy of an unemployed worker.

The methods leading to (13) and (14) now imply

$$
\begin{aligned}
r U & =b+\alpha_{0} \int_{w_{R}}^{\infty}[W(w)-U] d F(w) \\
r W(w) & =w+\alpha_{1} \int_{w}^{\infty}\left[W\left(w^{\prime}\right)-W(w)\right] d F\left(w^{\prime}\right)+\lambda[U-W(w)],
\end{aligned}
$$

where the second term in (17) represents the event that an outside offer arrives while employed. Evaluating (17) at $w=w_{R}$ and combining it with (16),

$$
w_{R}=b+\left(\alpha_{0}-\alpha_{1}\right) \int_{w_{R}}^{\infty}\left[W\left(w^{\prime}\right)-W\left(w_{R}\right)\right] d F\left(w^{\prime}\right) .
$$

Observe that $w_{R}$ is greater or less than $b$ as $\alpha_{0}$ is greater or less than $\alpha_{1}$. Thus, when offers arrive more frequently while employed, individuals may accept $w<b$, just to get other offers.

To eliminate $W$ from (18), integrate by parts and insert $W^{\prime}(w)=\{r+$ $\left.\lambda+\alpha_{1}[1-F(w)]\right\}^{-1}$, which we get by differentiating (17), to yield

$$
w_{R}=b+\left(\alpha_{0}-\alpha_{1}\right) \int_{w_{R}}^{\infty}\left[\frac{1-F(w)}{r+\lambda+\alpha_{1}[1-F(w)]}\right] d w .
$$


This is a generalized version of (4), which was the special case $\alpha_{1}=0$. The basic results are similar to those in the simpler model, including $\partial w_{R} / \partial b>0$, but now we have interesting new predictions. For instance, when $w_{R}$ is higher workers do not accept low wage jobs, and so are less likely to experience jobto-job transitions. In other words, an increase in UI reduces turnover. The model is also obviously consistent with the facts that wages increase with tenure and turnover decreases with tenure since higher wage workers are less likely to leave. ${ }^{12}$

\subsubsection{On-the-job Wage Changes}

Another factor contributing to turnover is that $w$ may change at a given job. Suppose that according to a Poisson process with parameter $\lambda$, it changes from $w$ to a new $w^{\prime}$ drawn from $F\left(w^{\prime} \mid w\right)$. Notice the exogenous layoff model discussed above can be thought of a special case where $w^{\prime}=0$ with probability 1 , so that at rate $\lambda$ the job effectively disappears. Here, when the wage changes the worker can stay employed at $w^{\prime}$ or quit to unemployment, but in contrast to the model in the previous section, he cannot reject $w^{\prime}$ in favor of the current $w$. Ignoring on-the-job search for simplicity, we have

$$
r W(w)=w+\lambda \int_{0}^{\infty} \max \left[W\left(w^{\prime}\right)-W(w), U-W(w)\right] d F\left(w^{\prime} \mid w\right) .
$$

If $F\left(w^{\prime} \mid w_{2}\right)$ first order stochastically dominates $F\left(w^{\prime} \mid w_{1}\right)$ whenever $w_{2}>$ $w_{1}, W(w)$ is increasing and there is a single reservation wage $w_{R}$ for employed and unemployed agents. When employed at $w$, if the wage falls to $w^{\prime}<w_{R}$ the worker quits to unemployment. It is easy to see that the quit rate is decreasing in $w$. In the simplest case where $F\left(w^{\prime} \mid w\right)=F(w)$ (independence), we have

$$
w_{R}=b+\frac{\alpha-\lambda}{r+\lambda} \int_{w_{R}}^{\infty}\left(w-w_{R}\right) d F(w) .
$$

Notice $\lambda>\alpha$ implies that individuals accept $w<b$ - they prefer to take a job paying less than UI and wait for the wage to change rather than continuing to search while unemployed. An increase in $b$ still raises $w_{R}$, which in general affects transitions in and out of unemployment.

\footnotetext{
${ }^{12}$ To make search intensity endogenous with on-the-job search, let $g_{0}(\alpha)$ denote the cost of searching with intensity $\alpha$ for an unemployed worker and $g_{1}(\alpha)$ denote the cost for an employed worker. If $g_{0}^{\prime}(\alpha) \leq g_{1}^{\prime}(\alpha)$ for all $\alpha$, then unemployed workers will always search harder than employed workers. In any case, workers employed at higher wages search less, with search intensity declining to zero at very high wages.
} 


\subsubsection{On-the-job Learning}

Another framework with implications for turnover is the Jovanovic (1979a) learning model, which can rationalize some of the same observations the onthe-job search model explains. ${ }^{13}$ Jovanovic studies the case where agents have to learn in real time about how good they are at any job based on noisy productivity observations. Here we present the simple version in Wright (1986), where all learning takes place in one period (see Pries 2004 for an intermediate case). Assume an offer is a signal $\omega$, where $\omega$ is drawn from $H(\omega)$, depending on both the true wage $w$ and some noise; e.g., we could have $\omega=z w$ where $z$ is random. Using Bayes rule, we can back out the posterior distribution of the wage conditional on the signal, $F(w \mid \omega)$. Assume $F\left(w \mid \omega_{2}\right)$ first order stochastically dominates $F\left(w \mid \omega_{1}\right)$ whenever $\omega_{2}>\omega_{1}$.

In discrete time, the value of search is now

$$
U=b+\beta \int_{0}^{\infty} \max \{\mathbb{E}[W(w) \mid \omega], U\} d H(\omega) .
$$

The value of employment at a known $w$ is given by

$$
W(w)=w+\beta \max [W(w), U],
$$

since the worker can stay or quit. If he quits, his payoff is $U$, assuming he must wait one period for the next offer. Since $W(w)$ is increasing, stochastic dominance implies $\mathbb{E}[W(w) \mid \omega]$ is increasing in $\omega$. Hence there is a reservation signal $\omega_{R}$ such that offers should be accepted if $\omega \geq \omega_{R}$. Once $w$ is revealed, the worker quits if $w<w_{R}$. Notice that in this model workers may willingly accept jobs they would prefer to reject if information were perfect, and viceversa. Of course these effects are not symmetric: a bad job that is accepted soon leads to a quit; a good job that is rejected is lost forever.

More general learning models have the implication that reservation signals increase with tenure. This is because at the beginning of an employment

\footnotetext{
${ }^{13}$ See also Wilde (1979) and Jovanovic (1979b). Also, note that the kind of learning we consider here is distinguished from learning about the distribution $F$ while searching, which is also interesting; Burdett-Vishwanath (1998a) provide an example and references. It is worth mentioning that with learning about $F$, it is not even guaranteed that a reservation strategy will be optimal. Suppose, e.g., we know either: a) $w=w_{0}$ with prob 1; or b) $w=w_{1}$ with prob $\pi$ and $w=w_{2}$ with prob $1-\pi$. If $w_{2}>w_{1}>w_{0}$ and $\pi$ is small, it can be optimal to accept $w_{0}$ but not $w_{1}$ since an offer of $w_{1}$ signals that there is a good chance of getting $w_{2}$. Rothschild (1974) gives conditions to guarantee a reservation policy is optimal.
} 
spell there is a lot of uncertainty, so a low value of the signal does not necessarily imply that things are so bad. Similarly, a good signal is also not that informative, but since the worker can always quit there is an option value to staying. The more that is known about a situation, the more demanding one tends to be. Individuals with a long tenure at a job have already learned a lot and so they are less likely to quit. Furthermore, given that they are still there, they are more likely to be earning higher wages. Hence, this model also predicts quit rates fall and wages rise with tenure.

\subsection{Discussion}

There are many other interesting applications and generalizations of the basic model that we do not have space to cover. ${ }^{14}$ Suffice it to say that the framework would seem to have appeal for both micro and macro economists. For the former there are explicit predictions about things like individual labor market histories and wages; for the latter there is a foundation for a model of the "natural" rate of unemployment and how it is affected by policies such as changes in UI. Despite this, these models are not fully satisfactory for our purposes, because they are decision-theoretic (single-agent) models. For the remainder of the essay we want to move to equilibrium models.

We emphasize that the issue is not general versus partial equilibrium per se. For example, there is not necessarily a problem of internal consistency with assuming $F$ is given exogenously, as we can simply consider workers searching for jobs in nature say, good fishing spots. ${ }^{15}$ The more interesting issue is that one might want to allow $F$ to change endogenously with changes in policy, rather than simply assuming it is given by nature. To this extent we want models where wages are endogenous. Similarly we want models where the rates at which matches form and break up are endogenous. We have already discussed how we can make these things depend on workers'

\footnotetext{
${ }^{14}$ For example, one can consider more complicated dynamic versions of the problem, including the case where offers are serially correlated as in Lippman-McCall (1976b), Jovanovic (1987) and Lippman-Mamer (1989). Or one can study the case where UI varies over time as in Burdett (1979), Mortensen (1977), Albrecht-Vroman (2000) and ColesMasters (2000). Also, there are dynamic extensions such as "systematic search" where you first look at the locations that are best according to a prior, and if those are unsuccessful you proceed to other locations, typically lowering your reservation wage along the way, as in Salop (1973).

${ }^{15}$ This is one interpretation of Ljungqvist and Sargent (1998), who use a version of the model described above to discuss macro issues.
} 
behavior, including endogenous search intensity, on-the-job search, etc., but it seems clear that firms' behavior may also have an impact on them. When we say we want to move to equilibrium models, we mean that we want to get firms involved more explicitly.

However, there is no single way to proceed. Any equilibrium search model is going to require that we confront several issues, including two that we will emphasize: 1 . how do parties meet; and 2 . how do they determine wages. We will consider various assumptions along these lines. Although some people may prefer a single "one-size-fits-all" model, we think that it is a virtue of the approach that there are different sets of assumptions at our disposal. Given there is variation in actual wage setting practice, and the process by which workers and firms get together, we need to be flexible in our theories, and we want to understand how variation in assumptions influences outcomes. Moreover, all of the models discussed below are really just different ways of embedding workers, each of whom solves some version of the basic search problem studied above, into an environment where firms make interesting decisions.

\section{Random Search and Bargaining}

This section discusses a prominent line of research emanating from the work of Pissarides $(1985,2000)$, that studies underlying determinants of offer arrival rates, match dissolution rates, and wages. We will present a sequence of models that emphasize different margins, including entry by firms, the decision to consummate matches, and the decision to terminate matches. Before we do so, as we just said above, there are two key issues that need to be addressed: how do workers and firms meet, and how are wages determined. This class of models assumes meeting rates are determined through a matching function and wages through bargaining. We begin with these ideas.

\subsection{The Matching Function}

Suppose that at some point in time there are $v$ vacancies posted by firms looking for workers and $u$ unemployed workers looking for jobs. ${ }^{16}$ Building on ideas in Diamond (1981, 1982a,b), Mortensen (1982a,b), Pissarides (1984,

\footnotetext{
${ }^{16}$ For now we assume search intensity is fixed, but see Section 8 for a matching function where it is endogenous.
} 
1985) and elsewhere, we assume the number of contacts between firms and workers is given by a matching technology $m=m(u, v)$. This function is an exogenous specification, like a production function. Assuming all workers are the same and all firms are the same, the arrival rates for unemployed workers and employers with vacancies are then given by

$$
\alpha_{w}=\frac{m(u, v)}{u} \text { and } \alpha_{e}=\frac{m(u, v)}{v} .
$$

It is standard to assume the function $m$ is continuous, non-negative, increasing in both arguments and concave, with $m(u, 0)=m(0, v)=0$ for all $(u, v)$. In discrete-time models we also assume $m(u, v) \leq \min \{u, v\}$. It is also convenient to assume $m$ displays constant returns to scale, i.e. $\chi m(u, v)=m(\chi u, \chi v)$. While alternative assumptions are interesting - e.g. increasing returns potentially generates multiple equilibria, as emphasized by Diamond - constant returns is not inconsistent with the empirical work going back to Pissarides (1986) and Blanchard-Diamond (1989) (see the survey by Petrongolo-Pissarides 2001). Also, in our context, constant returns generates a big increase in tractability. In particular, it implies that $\alpha_{w}$ and $\alpha_{e}$ depend only on the ratio $v / u$, often referred to as a measure of market tightness, where $\alpha_{w}$ is an increasing and $\alpha_{e}$ a decreasing function of $v / u$. Equivalently, there is a continuous, decreasing, and 1-to-1 mapping between $\alpha_{w}$ and $\alpha_{e}$, which will be very useful below.

The meeting technology is meant to represent in a simple if somewhat reduced-form fashion the notion that it takes time for workers and firms to get together. Just as a production function maps labor and capital into output, $m$ maps search by workers and firms into meetings. There are papers that model this more deeply, some of which we discuss below. But starting with an exogenous matching function allows us to be agnostic about the actual mechanics of the process by which agents meet. An advantage of this approach is that it is a flexible way to incorporate features that seem desirable e.g. more search by either side of the market yields more meetings - and one can regard the exact specification as an empirical issue. This may make matching a bit of a black box, but it has proved to be a very useful approach. ${ }^{17}$

\footnotetext{
${ }^{17}$ We do want to mention an interesting alternative to the specification in the text, where the number of meetings depends on the flows of new unmatched workers and firms rather than the stocks of existing unemployment and vacancies; see Coles-Smith $(1996,1998)$. See Lagos (2000) for another alternative approach.
} 


\subsection{Bargaining}

Now we consider the situation of a worker and a firm who have met and have an opportunity to produce a flow of output $y$. Suppose that if the worker gets $w$, his expected lifetime utility is $W(w)$ while the firm earns expected discounted profit $J(\pi)$, where $\pi=y-w$ (again $W$ stands for the value of working, and now $J$ stands for the value to the firm of a job that is filled). If they fail to reach agreement, the worker's payoff falls to $U$ and the firm's to $V$ (again $U$ stands for the value of unemployment, and now $V$ stands for the value to the firm of a vacancy). We will soon determine $U$ and $V$ endogenously, but for now take them as given. We are of course interested in situations where $W(w)>U$ and $J(y-w)>V$ for some $w$, so that there is something to bargain over.

A standard approach is to assume that the wage is determined by the generalized Nash bargaining solution with threat points $U$ and $V$,

$$
w=\arg \max [W(w)-U]^{\theta}[J(y-w)-V]^{1-\theta},
$$

where $\theta \in(0,1)$ is the worker's bargaining power. The solution to the maximization problem satisfies

$$
\theta[J(y-w)-V] W^{\prime}(w)=(1-\theta)[W(w)-U] J^{\prime}(y-w),
$$

which can be solved for $w$. Since it is an important building block in this class of models, and since wage determination is one of the key themes of this essay, we think that it is important to discuss the Nash bargaining solution carefully.

Nash (1950) did not actually analyze the bargaining process, but took as given four simple axioms and showed that his solution is the unique outcome satisfying these axioms. ${ }^{18}$ The solution, while elegant and practical, is again a bit of a black box. However, as is well known, one can provide a gametheoretic description of the bargaining process along the lines of Rubinstein (1982) that has a unique subgame perfect equilibrium that approximates the Nash solution. That is, as the time between counteroffers in the negotiation game becomes small, the equilibrium outcome converges to that predicted by

\footnotetext{
${ }^{18}$ Nash actually showed that the unique outcome consistent with his axioms has $\theta=1 / 2$. Relaxing his symmetry axiom, $(25)$ with any $\theta \in(0,1)$ satisfies the other axioms, and this is what is called the generalized Nash solution. See Osborne-Rubinstein (1990).
} 
the Nash solution, for particular choices of the threat points and bargaining power that depend on the details of the underlying game. ${ }^{19}$

For instance, suppose that each agent has a given probability of proposing (as opposed to responding to) an offer in each round of the bargaining game; other things being equal, this bargaining game generates the same outcome as the Nash solution in which the bargaining power equals that probability. Of course, this only pushes $\theta$ one level back - where does that probability come from? In fact the nature of bargaining may well differ across industries, countries, and so on, and varying $\theta$ is one way to try and capture this. Also, at least in simple models, as we vary $\theta$ between 0 and 1 we trace out the set of bilaterally efficient and incentive compatible employment relationships, which would seem to cover the cases of interest. So, while Nash bargaining may not be the last word on wage determination, we think that it has proven (like the matching technology) to be a useful approach that one ought to know.

To proceed, suppose as above that workers and firms are risk-neutral, infinitely-lived, and discount future payoffs in continuous time at rate $r$, and that matches end exogenously at rate $\lambda$. Then we have

$$
\begin{aligned}
r W(w) & =w+\lambda[U-W(w)] \\
r J(\pi) & =\pi+\lambda[V-J(w)] .
\end{aligned}
$$

This implies $W^{\prime}(w)=-J^{\prime}(\pi)=\frac{1}{r+\lambda}$. Inserting these into (26) and rearranging gives

$$
W(w)=U+\theta[J(y-w)-V+W(w)-U] .
$$

This says that in terms of total lifetime expected utility, the worker receives his threat point $U$ plus a share of the surplus, defined by

$$
S(y)=J(y-w)-V+W(w)-U .
$$

Also note from (27) and (28) that we can write $W(w)-U=\frac{w-w_{R}}{r+\lambda}$ and $J(\pi)-V=\frac{\pi-\pi_{R}}{r+\lambda}$ where $w_{R}$ and $\pi_{R}$ are reservation wage and profit levels for the worker and firm. Then (25) reduces to

$$
w=\arg \max \left[w-w_{R}\right]^{\theta}\left[y-w-\pi_{R}\right]^{1-\theta},
$$

\footnotetext{
${ }^{19}$ Again see Osborne-Rubinstein (1990), although note that they only consider stationary environments; for the nonstationary case see Coles-Wright (1998).
} 
which has the solution

$$
w(y)=w_{R}+\theta\left(y-\pi_{R}-w_{R}\right)
$$

Hence, in this model the Nash solution also splits the surplus in terms of the current period utility. Notice that $w(y) \geq w_{R}$ iff $y \geq y_{R}=\pi_{R}+w_{R}$. Similarly, $\pi(y)=y-w(y) \geq \pi_{R}$ iff $y \geq y_{R}$. This implies the worker and firm necessarily agree to consummate a relationship iff $y \geq y_{R}$.

\subsection{Job Creation}

We now combine matching and bargaining in a model where a firms' decision to post a vacancy is endogenized using a free entry condition. ${ }^{20}$ Let $k$ be the flow cost of posting a vacancy. Let $y$ be the output of any match. All matches face an exogenous breakup rate $\lambda$. There is a unit mass of homogeneous workers, and unmatched workers search costlessly, while matched workers cannot search. We focus here on steady states, and let $u$ and $v$ represent steady-state levels of unemployment and vacancies. The steady-state unemployment rate is $u=\lambda /\left(\lambda+\alpha_{w}\right)$, where $\alpha_{w}=m(u, v) / u$ and $m$ is the meeting technology. As discussed above, assuming constant returns, once we know $\alpha_{w}$ we know $\alpha_{e}$ since both are functions of $u / v$.

The value of posting a vacancy is

$$
r V=-k+\alpha_{e}[J(\pi)-V]
$$

since it costs $k$ and the job is filled at rate $\alpha_{e}$. As free entry drives $V$ to 0 , we need not keep track of $V$, and we can write (33) as

$$
\alpha_{e} J(\pi)=k
$$

Also, the value of unemployment satisfies

$$
r U=b+\alpha_{w}[W(w)-U],
$$

while the equations for $W$ and $J$ are unchanged from (27) and (28). Formally, an equilibrium includes the value functions $(J, W, U)$, the wage $w$, and the

\footnotetext{
${ }^{20}$ In this basic version of the model, entry by firms is (almost) the only endogenous variable, but in this or any other version one can alternatively assume a fixed number of firms, and equilibrium will then determine $V$ endogenously.
} 
unemployment and vacancy rates $(u, v)$, satisfying Bellman's equations, the bargaining solution, free entry and the steady-state condition. ${ }^{21}$

Next we discuss how to solve the model. One approach would be to try to find the equilibrium wage. Start with some arbitrary $w$, solve $(28)$ for $J(\pi)$, and then use (34) to solve for $\alpha_{e}$ and $\alpha_{w}$. This determines $W$ and $U$. This $w$ is an equilibrium iff the implied values for $J, W$ and $U$ are such that the bargaining condition holds. While this works, here we bypass $w$ by working directly with the surplus $S$. Substitution of $J$ and $W$ from (27) and (28) into (30) yields

$$
(r+\lambda) S(y)=y-r U
$$

Now (29) allows us to rewrite (35) as $r U=b+\alpha_{w} \theta S(y)$. Now (36) gives

$$
\left(r+\lambda+\alpha_{w} \theta\right) S(y)=y-b .
$$

The next step generally in this method is to obtain expressions that characterize optimal choices for each of the decisions made outside of a match, given $S$. In this particular model the only such decision is whether to post a vacancy. Using (34) and the fact that bargaining implies $J[\pi(y)]=$ $(1-\theta) S(y)$, we have

$$
k=\alpha_{e}(1-\theta) S(y) .
$$

Now (37) and (38) completely characterize equilibrium. In this simple model we can combine them as

$$
\frac{r+\lambda+\alpha_{w} \theta}{(1-\theta) \alpha_{e}}=\frac{y-b}{k}
$$

Under standard regularity conditions a unique solution for $\alpha_{w}$ exists. From this we can recover the wage,

$$
w(y)=y-(r+\lambda)(1-\theta) S(y) .
$$

A number of results now follow easily. For example, an increase in $b$ reduces the rate at which workers contact firms $\alpha_{w}$, raises the rate at which

\footnotetext{
${ }^{21}$ Although we focus on steady states, dynamics here are straightforward. The key observation is that the free entry condition pins down $\alpha_{e}$ and therefore $\alpha_{w}$. Hence, given any initial unemployment rate, vacancies adjust so that $u / v$ jumps to the steady state level, which implies all other variables are constant along the path as $u$ and $v$ converge to their steady state levels. See Mortensen $(1989,1999)$ for models that are related, but have dynamics that can be much more complicated.
} 
firms contact workers $\alpha_{e}$, reduces $S(y)$, and raises $w(y)$. The conclusion that unemployment duration and wages increase with UI is similar to what we found in the single-agent model with endogenous search intensity, but the interpretation here is different. In that model an increase in $b$ induced workers to reduce their search intensity and raise their reservation wage. Here an increase in $b$ raises the bargained wage, which discourages job creation, thereby increasing unemployment duration. ${ }^{22}$

In the above model it takes time for workers and firms to get together, but every contact leads to a match, and $w$ is the same in every match. This seems quite special when compared to the models in Sections 2 and 3 , since it corresponds to workers sampling from a degenerate distribution. Moreover, in applications, changes in the probability that a contact leads to job creation may be important. Hence we want to generalize things so that not every contact results in a match and not every match yields the same wage. Thus, assume that when a worker and firm meet they draw a match-specific productivity $y$ from some distribution $F$, where for simplicity $y$ is observed by both parties and constant for the duration of the match. We know from Section 4.2 that workers and firms agree to match iff $y \geq y_{R}$, where $y_{R}$ will be characterized below.

An equilibrium is described by the same objects as above, except now $J$, $W$, etc. are indexed by $y$, plus the new variable $y_{R}$. Equilibrium will also determine the distribution of productivity across existing relationships, or equivalently, given $w(y)$, the wage distribution $G(w)$. The only things that change from the previous model are Bellman's equation for an unemployed worker and the free entry condition, which become

$$
\begin{aligned}
r U & =b+\alpha_{w} \int_{y_{R}}^{\infty}[W(y)-U(y)] d F(y)=b+\alpha_{w} \theta \int_{y_{R}}^{\infty} S(y) d F(y) \\
k & =\alpha_{e} \int_{y_{R}}^{\infty} J(y) d F(y)=\alpha_{e}(1-\theta) \int_{y_{R}}^{\infty} S(y) d F(y) .
\end{aligned}
$$

To solve this model, combine these to get $r U=b+\frac{\alpha_{w} \theta k}{\alpha_{e}(1-\theta)}$, then substitute into (36) to get

$$
(r+\lambda) S(y)=y-b-\frac{\alpha_{w} \theta k}{\alpha_{e}(1-\theta)} .
$$

\footnotetext{
${ }^{22}$ One special case merits mention: suppose $m(u, v)=\mu v$, so vacancies are the only input into the matching function. Then an increase in $b$ reduces $v / u$, which increases $u$, but has no effect on $w$ or workers' payoffs conditional on employment status.
} 
In particular, $y_{R}$ satisfies $S\left(y_{R}\right)=0$, or

$$
y_{R}=b+\frac{\alpha_{w} \theta k}{\alpha_{e}(1-\theta)} .
$$

Finally, since $S^{\prime}(y)=\frac{1}{r+\lambda}, S(y)=\left(y-y_{R}\right) /(r+\lambda)$ for $y>y_{R}$, and (42) can be written

$$
(r+\lambda) k=\alpha_{e}(1-\theta) \int_{y_{R}}^{\infty}\left(y-y_{R}\right) d F(y) .
$$

We can now solve for $y_{R}$ and $\alpha_{w}$ from (44) and (45). The first of these equations describes an increasing relationship between $\alpha_{w}$ and $y_{R}$ (when it is easier for a worker to find a job, he is more willing to turn down a potential match with low productivity). The second gives a decreasing relationship between $y_{R}$ and $\alpha_{w}$ (when $y_{R}$ is higher, meetings are less profitable for firms so they post fewer vacancies). There exists a unique equilibrium under standard conditions. One can now recover the wage function: since $w\left(y_{R}\right)=y_{R}$ and $w^{\prime}(y)=\theta$ if $y>y_{R}$, we have $w(y)=y_{R}+\theta\left(y-y_{R}\right)$. Since the distribution of match productivity is $F(y)$ truncated at $y_{R}$, the equilibrium wage distribution $G(w)$ is given by $F(y)$ and $w(y)$.

It is now easy to discuss turnover and wages. For example, an increase in $b$ shifts (44) but not (45), resulting in an increase in $y_{R}$, a reduction in $\alpha_{w}$, and a reduction in $H=\alpha_{w}\left[1-F\left(y_{R}\right)\right]$. From a worker's perspective, things here closely resemble the single-agent problem, in the sense that he receives offers at rate $\alpha_{w}$ from a given distribution and needs to decide which ones to accept, although of course here the wage distribution and arrival rate are endogenous. As in the single-agent problem, two things need to happen in order for a worker to transit from unemployment to employment: he needs to contact a firm, and the draw $y$ needs to be good enough.

\subsection{Job Destruction}

We now endogenize the job destruction rate, following Mortensen-Pissarides (1994), by incorporating on-the-job wage changes as in Section 3.2.2. ${ }^{23}$ The resulting framework is interesting because it captures endogenously both the flows into and out of unemployment. Given that these flows vary a lot across

\footnotetext{
${ }^{23}$ Other extensions from Section 3 can also be added, including on-the-job search (Pissarides 1984,1994) and learning (Pries 2004; Pries-Rogerson 2000).
} 
countries and over time, it allows one to begin thinking formally about various factors that can account for these differences. To proceed, let $y$ be the current output produced in a match and assume that at rate $\lambda$ we get a new draw from $F\left(y^{\prime} \mid y\right)$, with $y^{\prime} \in[0, \bar{y}]$ for some $\bar{y}$. Also assume $F\left(y^{\prime} \mid y_{2}\right)$ first order stochastically dominates $F\left(y^{\prime} \mid y_{1}\right)$ whenever $y_{2}>y_{1}$ to ensure a reservation strategy. It remains to specify the level of productivity in new matches. One can assume new matches start at some random $y$, but here we assume they begin with the same $y_{0}$ (some papers assume $y_{0}=\bar{y}$ ).

An equilibrium is defined as the natural extension of the previous model, and we can jump directly to the equation for the surplus

$$
(r+\lambda) S(y)=y-r U+\lambda \int_{y_{R}}^{\bar{y}} S\left(y^{\prime}\right) d F\left(y^{\prime} \mid y\right) .
$$

Since $r U=b+\alpha_{w} \theta S\left(y_{0}\right)$, this can be rewritten

$$
(r+\lambda) S(y)=y-b-\alpha_{w} \theta S\left(y_{0}\right)+\lambda \int_{y_{R}}^{\bar{y}} S\left(y^{\prime}\right) d F\left(y^{\prime} \mid y\right)
$$

To close the model we again use free entry,

$$
k=\beta \alpha_{e}(1-\theta) S\left(y_{0}\right) .
$$

Finding equilibrium amounts to solving (48) and (47) for $y_{R}$ and $\alpha_{w}$.

The argument is slightly more complicated here because we are now looking for a fixed point in a system of functional equations - (47) defines both $y_{R}$ and $S(y)$ as functions of $\alpha_{w}$. Nevertheless, an increase in $\alpha_{w}$ reduces $S(y)$ for all $y$ and hence raises the reservation wage $y_{R}$. Thus, (47) describes an increasing relationship between $\alpha_{w}$ and $y_{R}$, called the job destruction curve. At the same time, (48) indicates that when $\alpha_{w}$ is higher $S\left(y_{0}\right)$ must be higher, so from (47) $y_{R}$ must be lower, and this defines a decreasing relationship between $\alpha_{w}$ and $y_{R}$ called the job creation curve. The intersection of these curves gives steady-state equilibrium, which exists uniquely under standard conditions. See Mortensen-Pissarides $(1994,1999 b)$ for further discussion.

\subsection{Extensions and Applications}

Cole-Rogerson (1999) discuss how well the model accounts quantitatively for the behavior of job creation and destruction over the business cycle. Shimer 
(2004) also studies the model quantitatively, pointing out that it predicts relatively small fluctuations in $\alpha_{w}$ in response to reasonably calibrated shocks to $y$ or $\lambda$. Costain-Reiter (2003) argue that if one calibrates to generate realistic business cycle fluctuations in the job-finding rate, the model predicts an unrealistically large impact of UI on the job-finding rate. Hall (2003) pursues one possible resolution of this puzzle by assuming wages are more backward looking than Nash bargaining permits. He shows that a modification to the wage equation can significantly improve the performance of this model. Other authors who use the framework for business cycle analysis include Andolfatto (1996), Merz $(1995,1999)$ and den Haan-Ramey-Watson (2000).

One issue that has received attention in business cycle versions of these models is "cleansing" - the notion that in bad economic times low productivity matches are destroyed, as discussed in Caballero-Hammour (1994,1996). More recently, Barlevy (2002) argues that recessions are "sullying" rather than "cleansing" because they inhibit workers' ability to move up the job ladder. We alluded earlier to a literature that uses these models to study the behavior of worker and job flows across countries as well as over the business cycle. Millard-Mortensen (1997) show how different policy regimes in the US and UK can account for their different labor market outcomes. Delacroix (1999, 2003) and Blanchard-Portugal (2001) study the effect of various employment protection policies.

There is also a literature that allows heterogeneous workers and firms. Acemoglu (1999, 2001) and Albrecht-Vroman (2002) consider workers that differ in skill and show how this can affect the types of jobs firms create and the wage and unemployment levels for different groups. Mortensen-Pissarides (1999c) examine how various policies impact differently across skill groups. Shimer (1999) considers heterogeneous workers, allows multiple workers to show up for a given vacancy, and studies how this can affect unemployment dynamics for low-skill workers. Shimer-Smith (2000) ask whether matching is assortative in an environment in which workers and firms are heterogeneous. While we cannot do justice to all the work in the area, we want to say that it represents a very active and productive research area. ${ }^{24}$

\footnotetext{
${ }^{24}$ A related literature follows the Lucas-Prescott (1974) approch, which does not use a matching function (although it could) and assumes wages are determined competitively; recent examples include Greenwood-MacDonald-Zhang (1996), Gomes-Greenwood-Rebelo (2001) and Alvarez-Veracierto (1999). Another related model was presented by Howitt and McAfee (1987) and Howitt (1988).
} 


\section{$5 \quad$ Directed Search and Posting}

A key aspect of any decentralized mechanism in an equilibrium search model is wage determination. In the previous section we studied bargaining, and here we discuss another possibility: ex ante wage posting. In addition to posting, the models in the section also adopt the idea of directed search, which means that agents can, as the name suggests, direct their search efforts towards particular wages. Following Moen (1997) and Shimer (1996), models with the combination of posting and directed search are referred to in the literature since as competitive search models. It is important to emphasize that it is the combination of these features that is important; in Section 7 we will study posting with random search, which is quite different.

The literature has proposed several alternative but equivalent approaches to competitive search. One approach posits a group of agents called market makers who publicly set up submarkets with posted wages, with the property that any match consummated in their submarket must be at the posted wage. Within each submarket there is still random matching with a constant returns function $m(u, v)$, so that $q=u / v$ determines the meeting rates $\alpha_{w}$ and $\alpha_{e}$ (obviously $q$ is the inverse of market tightness as defined in Section 4.1). Each unemployed worker and each firm with a vacancy take as given $w$ and $q$ in every submarket, and go to the one offering the highest expected utility. In equilibrium, two things are true: $q$ in each submarket must be consistent with what agents take as given; and no market maker can post $w$ a different from what is already posted and attract both workers and employers. ${ }^{25}$

Another approach supposes that employers themselves post wages, and unemployed workers direct their search to the most attractive wage offers. A high posted $w$ attracts more applicants, which reduces workers' contact rate $\alpha_{w}$ and raises the employer's contact rate $\alpha_{e}$. In equilibrium, workers are indifferent about where to apply, at least among posted wages that attract some workers. Firms choose wages to maximize expected profit. Still another approach assumes that workers post wages, and firm apply (direct their search) to workers. As we said, these approaches are equivalent, in the sense that they give rise to identical equilibrium conditions. Hence for brevity in this section we consider only the case where firms post wages.

\footnotetext{
${ }^{25}$ The idea here is that market makers compete to attract workers and firms to their submarkets since they can charge them an entrance fee, but in equilibrium this fee is 0 due to free entry into the market making business.
} 


\subsection{A One-Shot Model}

We first illustrate how the basic mechanism works in a static setting, then extend things to a dynamic framework in order to facilitate comparison with other models. Thus, at the beginning of the period, there are large numbers $u$ and $v$ of unemployed workers and vacancies, and we let $q^{*}=u / v$. Each firm with a vacancy must pay cost $k$, and we can either assume free entry (making $v$ endogenous) or fix the number of vacancies. Any match within the period produces output $y$. At the end of the period, unmatched workers get $b$, while unmatched vacancies get 0 . Then the model ends.

First consider a worker facing a menu of different wages. Let $U$ denote the highest value that he can get by applying for a job at some firm. Then a worker is willing to apply to a particular job offering a wage $w \geq b$ only if he believes the queue length $q$ at that job-i.e. the number of workers who apply - is sufficiently small. Equivalently, he is willing to apply only if the hiring probability $\alpha_{w}(q)$ is sufficiently large, in the sense that

$$
U \leq \alpha_{w}(q) w+\left[1-\alpha_{w}(q)\right] b .
$$

In fact, if this inequality is strict, all workers would want to apply to this firm, reducing the right hand side. Therefore, in equilibrium, if any workers apply to a particular job, $q$ will adjust to satisfy (49) with equality.

From an employer's perspective, (49) describes how a change in his wage $w$ affects his queue length $q$. Therefore he chooses $w$ to maximize

$$
V=\max _{w, q}-k+\alpha_{e}(q)(y-w)
$$

taking (49) as a constraint. Eliminating $w$ using (49) at equality, and also using $\alpha_{e}(q)=q \alpha_{w}(q)$, we get

$$
V=\max _{q}\left\{-k+\alpha_{e}(q)(y-b)-q(U-b)\right\} .
$$

The first order condition is

$$
\alpha_{e}^{\prime}(q)(y-b)=U-b
$$

Since $\alpha_{e}$ inherits the concavity of the matching function, this is necessary and sufficient for profit maximization. 
In particular, it implies that all employers choose the same $q$, which in equilibrium must equal the economy-wide $q^{*}$. Hence (52) pins down the equilibrium value of $U$. Then (49) at equality determines the market wage

$$
w^{*}=b+\frac{q^{*} \alpha_{e}^{\prime}\left(q^{*}\right)}{\alpha_{e}\left(q^{*}\right)}(y-b)=b+\varepsilon\left(q^{*}\right)(y-b),
$$

where $\varepsilon\left(q^{*}\right)=\frac{q^{*} \alpha_{e}^{\prime}\left(q^{*}\right)}{\alpha_{e}\left(q^{*}\right)}$ is the elasticity of $\alpha_{e}\left(q^{*}\right)$, which is in $(0,1)$ by our assumptions on $m$. Hence, $w^{*} \in(b, y)$. Comparing (53) with the results in Section 4.2, notice that this wage rule operates as if the worker and firm bargained over the gains from trade, with the workers' share $\theta$ given by the elasticity $\varepsilon\left(q^{*}\right)$; this has important implications for the efficiency of competitive search, as we discuss below.

Substituting (53) into (50) pins down

$$
V=-k+\left[\alpha_{e}\left(q^{*}\right)-q^{*} \alpha_{e}^{\prime}\left(q^{*}\right)\right](y-b) .
$$

If the number of vacancies $v$ is fixed this gives profit; or we can use free entry $V=0$ to endogenize $v$ and hence $q^{*}$. In either case the model is simple to apply, and can be used, e.g., to discuss the effects of changes in $b$. Indeed, things look a lot like a one-shot version of the model in the previous section. ${ }^{26}$ There is one key difference, however: $w$ is determined as a share of the surplus with the share $\theta$ now endogenously determined by $\varepsilon\left(q^{*}\right)$.

Some interesting issues that show up even in this simple static model. Montgomery (1991) had a nascent version of the above model (see also Peters 1984, 1991). He starts by exploring the case with two unemployed workers and two vacancies, where firms post wages and then each worker applies for a job. A firm that receives at least one application fills the job at the posted $w$, and if more than one worker applies the firm randomly selects one. ${ }^{27}$ Suppose firms offer the same $w>0$. Then there are three Nash equilibria in the application subgame: worker 1 applies to firm 1 and worker 2 applies to firm 2; worker 1 applies to firm 2 and worker 2 applies to firm 1; and both workers use identical mixed strategies, applying to each firm with probability $1 / 2$. It seems reasonable to argue that the coordination implied by the first two equilibria is implausible, at least in a large labor market, and hence the

\footnotetext{
${ }^{26}$ We will discuss explicitly a one-shot version of the Pissarides model in Section 8.1.

${ }^{27} \mathrm{By}$ assumption here firms post wages rather than more general mechanisms. ColesEeckhout (2003) relax this (e.g., they allow $w$ to be contingent on the number of applicants who turn up) and show it does not affect the main conclusions.
} 
mixed-strategy equilibrium is the natural outcome (see Montgomery 1991 and Burdett-Shi-Wright 2001). This introduces a coordination friction, as more than one worker may apply for the same job.

Generalizing this reasoning, suppose there are $u$ unemployed workers and $v$ vacancies, for any $u$ and $v$. If each worker applies to each firm with equal probability, any firm gets a worker with probability $1-\left(1-\frac{1}{v}\right)^{u}$. By taking the limit of this expression as $u$ and $v$ go to infinity while $q=u / v$ remains fixed, we find that in a large market the fraction $\alpha_{e}(q)=1-e^{-q}$ of firms get a worker. This is a standard result in statistics: suppose there are $u$ balls independently placed with equal probability into each of $v$ urns. Then for large $u$ and $v$, the number of balls per urn is a Poisson random variable with mean $u / v$, and in particular a fraction $e^{-u / v}$ of the urns do not get any balls. For this reason, the matching process generated by this type of coordination friction is often called the urn-ball matching function. ${ }^{28}$

Because the urn-ball matching process provides an explicit microeconomic story of both meetings (a ball is put in a particular urn) and matches (a ball is chosen from that urn), it is suitable for environments with heterogeneous workers (not all balls are the same). For instance, suppose there are $u_{1}$ type 1 workers and $u_{2}$ types 2 workers, with $u=u_{1}+u_{2}$. If a firm hires a type 1 worker in preference to a type 2 worker whenever it receives an appropriate application, then it hires a type 1 worker with probability $1-$ $e^{-u_{1} / v}$ and a type 2 worker with probability $e^{-u_{1} / v}\left(1-e^{-u_{2} / v}\right)$. Summing these, it hires some worker with probability $1-e^{-u / v}$. This implies that an increase in the number of undesirable type 2 workers does not adversely affect the matching rate for desirable type 1 workers, but desirable workers adversely affect the employment rate of undesirable workers. See ColesEeckhout (2000), Shi (2002), and Shimer (2003) for more on competitive search models with heterogeneity.

There are several other generalizations of this matching process. BurdettShi-Wright (2001) let some firms hire multiple workers. Albrecht-Gautier-

\footnotetext{
${ }^{28}$ Notice that in the above discussion we ignored strategic interaction between firms: in maximizing (50) subject to (49), the firm takes as given that a worker's market payoff is $U$, but of course in general if any firm changes its $w$ then $U$ should change. BurdettShi-Wright (2001) solve the model with any finite number of firms and workers, where each firm must compute the effect of a change in its $w$ on the probability that any worker applies to each firm and on the implied $U$. In the limit as $u$ and $v$ grow, they show that the problem reduces to the one analyzed here, where firms treat $U$ as a parameter. This makes competitive search relatively simple with large markets.
} 
Vroman (2003) and Albrecht-Gautier-Tan-Vroman (2004) allow workers to make multiple applications. If workers can apply simultaneously for every job, this effectively flips the standard urn-ball problem around, so workers are urns and firms are balls, and a worker is employed if at least one firm offers him a job, which occurs with probability $1-e^{-v / u}$; this is explored in detail by Julien-Kennes-King (2000). The intermediate case in which workers can apply only for a subset of jobs delivers additional possibilities. In any event, directed search models seem like a potentially interesting way to get inside the black box of the matching process.

\subsection{A Dynamic Model}

To get something like the basic Pissarides model with directed search, start with an unemployed worker. Suppose he anticipates an unemploymentvacancy ratio $q$ and a wage $w$. Then

$$
\begin{aligned}
r U & =b+\alpha_{w}(q)[W(w)-U] \\
r W(w) & =w+\lambda[U-W(w)] .
\end{aligned}
$$

It will be convenient to combine these into

$$
r U=b+\frac{\alpha_{w}(q)(w-r U)}{r+\lambda} .
$$

Similarly, for firms

$$
\begin{aligned}
r V & =-k+\alpha_{e}(q)[J(y-w)-V] \\
r J(y-w) & =y-w+\lambda[V-J(y-w)] .
\end{aligned}
$$

Free entry $V=0$ yields

$$
k=\frac{\alpha_{e}(q)(y-w)}{r+\lambda} .
$$

Now suppose firms choose $w$ and $q$ to maximize $r V$, or equivalently by free entry, to maximize $\alpha_{e}(q)(y-w)$. They take (57) as given. Eliminating $w=r U+(r U-b)(r+\lambda) / \alpha_{w}(q)$ using the constraint, and again using $\alpha_{e}(q)=$ $q \alpha_{w}(q)$, we can reduce this to

$$
\max _{q}\left\{\alpha_{e}(q) \frac{y-r U}{r+\lambda}-q(r U-b)\right\} .
$$


The necessary and sufficient first order condition $\alpha_{e}^{\prime}(q)(y-r U)=(r U-$ $b)(r+\lambda)$ has a unique solution, so all firms choose the same $q$. Solving for

$$
r U=\frac{\alpha_{e}^{\prime}(q) y+b(r+\lambda)}{r+\lambda+\alpha_{e}^{\prime}(q)},
$$

it is now a matter of algebra to find $w$ and insert it into (60) to arrive at

$$
\frac{r+\lambda+\alpha_{e}^{\prime}(q)}{\alpha_{e}(q)-q \alpha_{e}^{\prime}(q)}=\frac{y-b}{k} .
$$

This pins down the equilibrium $q$, or equivalently the arrival rates $\alpha_{w}$ and $\alpha_{e}$. Under standard conditions the solution is unique. We can again perform our usual exercise of increasing $b$, with a similar result: it raises the $u / v$ ratio, which reduces $\alpha_{w}$, and through the zero profit condition increases $w$. But although the conclusions are similar to those reached in the random search model with bargaining, the economic mechanism is quite different. An increase in $b$ here makes workers more willing to accept an increase in the risk of unemployment in return for an increase in $w$. Firms respond by offering workers what they want-fewer jobs at higher wages.

\subsection{Discussion}

In addition to having a more explicit description of the matching process, an advantage of competitive search models is that they provide a deeper explanation for wages than bargaining, where $w$ divides the surplus into exogenous shares. Here workers face a trade-off between a higher $w$ and a lower probability of getting a job, while firms face a trade-off between profit and the probability of hiring. Competition among wage setters, whether these be firms, workers or market makers, yields a unique point along the indifference curves of both agents, optimally trading off wages and matching rates (see Section 8). However, perhaps a disadvantage of any posting model is that it makes a strong assumption when it says agents commit to the posted terms of trade. If the market is truly decentralized, what prevents them from trying to bargain for a different $w$ after they meet? ${ }^{29}$

\footnotetext{
${ }^{29}$ Another apparent drawback is that the simplest competitive search model predicts there is a single wage, but this is easily remedied. One can introduce match-specific productivity $y$, and have agents post a wage contract $w(y)$ rather than a single $w$. In equi-
} 
In terms of extensions, Shi $(2001,2002)$ and Shimer (2003) add heterogeneous agents to competitive search models, which introduces wage dispersion among heterogeneous workers, and among identical workers depending on their employer. Acemoglu-Shimer (1999) consider a model where workers are risk-averse, which has a similar basic structure except that it is no longer possible to eliminate the wage from the employer's objective function and solve the model explicitly. They show that an increase in risk-aversion reduces the equilibrium wage, while an increase in $b$ raises it. Put differently, market incompleteness lowers $w$, and this can potentially be offset through UI policy. Building on this, Acemoglu-Shimer (2000) show in a calibrated model UI can enhance productivity.

\section{Nontransferable Utility}

Economists usually model employment relationships under the assumption of transferable utility: if a worker and firm together produce $y$, it is divided between them so that the former gets $w$ and the latter $\pi=y-w$. Note that transferable utility in the jargon of the literature means perfectly linearly transferable: every increase in the worker's payoff comes 1-for-1 with a decrease in the firm's payoff. The above models all have this feature. However, it is clear that there can be aspects of employment relationships that do not fit this description, such as the job's location or how one gets along with one's boss. ${ }^{30}$ Moreover, it is not uncommon to observe regulations or wage-setting institutions that effectively fix $w$ or at least limit its flexibility for a given type of labor, including minimum wage laws, occupation- or industry-wide unions, and so on.

Motivated by these considerations, some researchers have explored labor market models with nontransferable utility. Moving beyond the labor market, many search-based models of the marriage market view nontransferable utility as the natural benchmark. Hence, it seems worth reviewing the framework. Note that while in general these models could assume util-

librium the worker and firm agree on whether to match, using a reservation productivity rule $y_{R}$. The exact structure of the wage contract is ambiguous, as long as the parties are risk neutral, but in any case the basic structure of the model is unchanged. On-the-job productivity changes also fit naturally and can generate wage dispersion.

${ }^{30}$ Even if you could get an increase in $w$ to compensate for not liking your boss, it is unlikely that every unit reduction in profit would yield a unit increase in your utility. 
ity is partially transferable, but just not linearly, the relevant results can be captured by the case where it is not transferable at all, so this is what we consider. One reason why nontransferable utility models are of particular interest is because they imply, in contrast to what we have seen elsewhere, that two parties may not agree on whether it is a good idea to form or maintain a relationship, thereby providing an alternative perspective on match creation and destruction.

\subsection{Homogeneous Agents}

Assume a large fixed number of workers and, for simplicity, an equal number of firms. Given workers and employers match in pairs, the fraction of workers who are unemployed is always equal to the fraction of employers with vacancies. Hence, with constant returns $m(u, u)=\alpha_{0} u$, so $\alpha_{e}=\alpha_{w}=\alpha_{0}$ is constant. Also assume for now that agents are ex ante identical, but each worker and employer has idiosyncratic tastes over matches. Following Burdett-Wright (1998), we formalize this by assuming that in a random meeting the payoffs to the worker and employer are given by $z_{w}$ and $z_{e}$, where $z_{w}$ and $z_{e}$ are independent draws from distributions $F_{w}$ and $F_{e}$. These payoffs can include both pecuniary and non-pecuniary attributes. Workers and employers die at rate $\delta_{w}$ and $\delta_{e}$, at which point they are replaced by identical agents who start life unmatched. There is also an exogenous separation rate $\lambda_{0}$. Agents cannot search while matched. ${ }^{31}$

A key feature of this setup is that when two agents meet their payoffs from consummating the match are not perfectly correlated - e.g. it may be good for the worker but not the firm, but by assumption there is nothing the former can do to affect the latter's evaluation (again, what is critical is only that they cannot transfer utility linearly). For a match to be consummated it must be mutually acceptable. Since a given agent may not be acceptable to everyone he meets, the effective arrival rates $\alpha_{w}$ and $\alpha_{e}$ are not necessarily the same as the contact rate $\alpha_{0}$, and need to be determined endogenously.

First note that every agent of type $j \in\{w, e\}$, taking $\alpha_{j}$ and $\delta_{j}$ para-

\footnotetext{
${ }^{31}$ We assume search is costless for all unmatched agents - e.g. there is no cost $k$ to posting a vacancy. Cornelius $(2000,2003)$ and Burdett-Imai-Wright (2004) relax some of these assumptions, and in particular allow on-the-job search. This leads to some interesting outcomes, including endogenous instability: it may be an (inefficient) equilibrium for a worker to be looking for another job because he believes his employer is trying to replace him, which is true because the worker is looking for a new job.
} 
metrically, faces a standard single-agent search problem, which is solved by a reservation utility level $w_{j}$ satisfying a version of (15) (although $w_{j}$ is a reservation utility level rather than a reservation wage, the same methods still). For a worker,

$$
w_{w}=b+\frac{\alpha_{w}}{r+\delta_{w}+\lambda_{w}} \int_{w_{w}}^{\infty}\left[1-F_{w}\left(z_{w}\right)\right] d z_{w},
$$

where $\alpha_{w}$ and $\lambda_{w}$ are his (expected) arrival and layoff rates. A symmetric equation holds for firms, giving their reservation utility level $w_{e}$.

In equilibrium, as we said, not all contacts result in an offer. For workers, $\alpha_{w}=\alpha_{0}\left[1-F_{e}\left(w_{e}\right)\right]$, since to get an offer they need a contact and the employer must be willing to hire them, which requires $z_{e} \geq w_{e}$. Also, even if $\lambda_{0}$ is exogenous, agents still have to worry about death on the other side of the market. Hence, for workers, e.g., $\lambda_{w}=\lambda_{0}+\delta_{e}$. Substituting $\alpha_{w}$ and $\lambda_{w}$ into (64) we have

$$
w_{w}=b+\frac{\alpha_{0}\left[1-F_{e}\left(w_{e}\right)\right]}{r+\delta_{w}+\delta_{e}+\lambda_{0}} \int_{w_{w}}^{\infty}\left[1-F_{w}\left(z_{w}\right)\right] d z_{w} .
$$

This implies a relation $w_{w}=\rho_{w}\left(w_{e}\right)$, which is the best response function of workers to the strategy of firms. ${ }^{32}$ Symmetrically, we have $w_{e}=\rho_{e}\left(w_{w}\right)$. A steady-state equilibrium is given by an intersection of the two best response functions in $\left(w_{w}, w_{e}\right)$ space.

One can show that equilibrium exists, and is unique under a log-concavity assumption. However, without log-concavity equilibrium is not generally unique. The intuition is as follows. Suppose one side of the market, say workers, are very demanding about the kinds of offers they accept $\left(w_{w}\right.$ is high). Then on the other side, firms get few offers, and so they cannot afford to be too demanding ( $w_{e}$ is low). This means the workers get plenty of offers, which justifies being demanding. So, high $w_{w}$ and low $w_{e}$ could be a selffulfilling prophecy, but so could exactly the opposite scenario. In general, the steady-state equilibrium unemployment (equals vacancy) rate is given by

$$
u^{*}=\frac{\lambda_{0}+\delta_{e}+\delta_{w}}{\lambda_{0}+\delta_{e}+\delta_{w}+H},
$$

\footnotetext{
${ }^{32}$ Here the dependence of $w_{w}$ on $w_{e}$ occurs only through $\alpha_{w}=\alpha_{0}\left[1-F_{e}\left(w_{e}\right)\right]$. But suppose $z$ changes during the relationship at rate $\lambda$, as in Section 3.22; then $\lambda_{w}=\lambda_{0}+$ $\delta_{e}+\lambda F_{e}\left(w_{e}\right)$. Hence, generally both the arrival and layoff rates for one side depend on strategies on the other side of the market.
} 
where $H=\alpha_{0}\left[1-F_{w}\left(w_{w}\right)\right]\left[1-F_{e}\left(w_{e}\right)\right]$ depends on which equilibrium we select. See Burdett-Wright (1998) for more discussion.

Even when there is a unique equilibrium, this model has interesting implications. A neat example is Masters (1999), who adds to the above framework an ex ante stage where the wage is determined endogenously, but still assumes that utility is nontransferable ex post when agents meet. Again under a log-concavity assumption, there is a unique symmetric equilibrium in the ex ante wage game, $w^{*}$. Given $w^{*}$, some meetings result in a match being consummated while others do not, depending on the random non-wage characteristics. His key result is that $w^{*}$ is less than the value that minimizes unemployment. Hence, an increase in the legislated minimum wage leads to a reduction in unemployment. ${ }^{33}$

\subsection{Heterogeneous Agents}

Burdett-Coles (1997) consider a version of the model in which individuals are ex ante heterogeneous (see also Eeckhout 1999). For simplicity, suppose that a random worker is valued by a firm at $z_{e} \sim F_{e}$, while a random employer is valued by a worker at $z_{w} \sim F_{w}$. In the homogeneous-agent model, all workers were equally likely to be accepted by any firm, and similarly for workers. Here better workers are acceptable to a larger subset of firms, and similarly better employers are acceptable to a larger set of workers. ${ }^{34}$ Hence we define an indicator function such that $a_{w}\left(z_{e}, z_{w}\right)=1$ if a type $z_{e}$ worker is willing to accept a type $z_{w}$ firm and 0 otherwise, and analogously define $a_{e}\left(z_{w}, z_{e}\right)$ as the willingness of a type $z_{w}$ firm to hire a type $z_{e}$ worker. Because utility is nontransferable, $a_{w}\left(z_{e}, z_{w}\right)$ need not equal $a_{e}\left(z_{w}, z_{e}\right)$.

As in previous models, agents use reservation strategies, so $a_{w}\left(z_{e}, z_{w}\right)=1$ iff $z_{w} \geq w_{w}\left(z_{e}\right)$ and $a_{e}\left(z_{w}, z_{e}\right)=1$ iff $z_{e} \geq w_{e}\left(z_{w}\right)$. The usual methods lead to the worker's reservation equation

$$
w_{w}\left(z_{e}\right)=b+\frac{\alpha_{0}}{r+\delta_{w}+\delta_{e}+\lambda_{0}} \int_{w_{w}\left(z_{e}\right)}^{\infty} a_{e}\left(z_{w}, z_{e}\right)\left[z_{w}-w_{w}\left(z_{e}\right)\right] d F_{w}\left(z_{w}\right),
$$

while firms have a similar equation for $w_{e}\left(z_{w}\right)$. Using $(67)$ it is straightforward to see that if a type $z_{e}^{\prime}$ worker has worse matching opportunities than a

\footnotetext{
${ }^{33} \mathrm{~A}$ similar story can be found in labor economics textbooks - i.e., market power by firms yields a $w$ that is too low, and hence a minimum wage can reduce unemployment. But these stories usually do not model unemployment in a serious way.

${ }^{34} \mathrm{An}$ interesting extension is to let agents choose their type, as in Burdett-Coles (2001).
} 
type $z_{e}$ worker -i.e. if $a_{e}\left(z_{w}, z_{e}\right) \geq a_{e}\left(z_{w}, z_{e}^{\prime}\right)$ for all $z_{w}$-then $z_{e}^{\prime}$ will have a lower reservation utility level than $z_{e}$, and if the matching opportunities are identical the reservation utility levels are identical. A similar result holds for employers.

This leads to the following insight: in equilibrium, workers and employers will endogenously match in classes. Within any class, any worker is willing to take any job and any employer is willing to hire any worker. A worker refuses a job from any employer in a lower class, while employers refuse to hire any worker in a lower class. In such an equilibrium all workers within a class have the same matching opportunities and therefore use the same reservation utility level. Workers in lower classes have worse matching opportunities and hence are willing to accept worse employers. The class structure follows immediately.

Burdett-Coles (1997) also show that multiple equilibria can exist. Individual reservation utility levels depend on matching opportunities as summarized by $F_{e}$ and $F_{w}$. But different individuals have endogenously different probabilities of finding a job. This implies matching decisions affect matching opportunities. Suppose, for example, that there are two types of workers and two types of jobs, with good workers and good employers scarcer than bad workers or bad employers. There can exist two equilibria. In one, all matches are consummated, so all workers have the same unemployment rate and all employers the same vacancy rate. In the other, good workers only match with good employers. Since good workers and good employers are scarce, these matches form less frequently than matches between bad workers and bad employers. This increases the presence of good types in the searching population, justifying individuals' decision to be choosy. ${ }^{35}$

\subsection{Discussion}

Nontransferable utility models can sometimes be interpreted, as in Masters' (1999), as describing situations where $w$ can adjust endogenously before meetings occur, but not after. In this sense they are similar to competitive search models, although the models in this section do not allow agents to direct their search. In the next section we also consider models where wages are not negotiable within the match and search is random, but the focus is on deriving equilibria with nondegenerate wage dispersion.

\footnotetext{
${ }^{35}$ Once again, one can show that log-concavity precludes this type of multiplicity.
} 


\section{Wage Dispersion}

We have considered theories with various assumptions about job creation, job destruction, and wage formation, but they all have one thing in common: two identical workers, with the same productivity at a given firm and the same outside options, earn the same $w$. In this sense the models do not provide a pure theory of wage dispersion. While obviously many models generate wage dispersion for heterogeneous workers, in this section we are interested in dispersion across workers of a given type. One reason such models are of interest is as follows. Early (decision-theoretic) work suggested that search is relevant only if the distribution from which you are sampling is non-degenerate. So theorists were naturally led to try to develop models of wage dispersion. It is also true that some people believe dispersion is a fact of life, and for them the issues were empirical rather than theoretical. ${ }^{36}$ In any case, a model of pure dispersion was the goal.

Diamond (1971) provides an early attempt to construct such a model, and although it did not work, it is very useful to understand why. Consider an economy where homogeneous workers each face the basic search problem described earlier. We do not give all the particulars here, since the underlying model is a special case of ones described in detail below, but the key is that the offer distribution $F$ is generated by wage-posting firms, each of which has a constant returns to scale technology with labor as the only input and commits to hire any worker it contacts who is willing to accept the posted wage. Consider an individual firm with productivity $p$, where the discussion does not depend on $p$ being constant or different across firms. Letting $F$ be the distribution of wages posted by other firms, he wants to maximize expected profit taking $F$ as given. By definition, in equilibrium every wage posted with positive probability earns the same profit and no other wage earns greater profit.

Diamond proves a rather striking result: there is a unique equilibrium, and in equilibrium all employers set the same wage, equal to workers' unemployment income, $w=b$. The proof is simple. Given any $F$, since workers

\footnotetext{
${ }^{36}$ As Mortensen (2003, p.1) reports, "Although hundreds if not thousands of empirical studies that estimate so-called human capital wage equations verify that worker characteristics that one could view as indicators of labor productivity are positively related to wages earned, the theory is woefully incomplete in its explanatory power. Observable worker characteristics that are supposed to account for productivity differences typically explain no more that 30 percent of the variation in compensation."
} 
are homogeneous they all choose the same reservation wage $w_{R}$. Clearly, no firm will post $w<w_{R}$ as this would mean they cannot hire, and no firm will post $w>w_{R}$ as they can hire every worker they contact at $w=w_{R}$. To see why it turns out that $w=b$ in equilibrium, consider an individual firm when all firms are posting $w>b$. If it deviates and offers a wage slightly less than $w$ it will still hire every worker it meets. Since this is true for any $w>b$, we must have $w=b$. There is a single wage. The model not only fails to rationalize wage dispersion in the data, it fails to explain why workers are searching in the first place! Many researchers subsequently tried to develop models where the equilibrium distribution is non-degenerate, and we will review several alternatives. ${ }^{37}$

\subsection{Worker Heterogeneity}

To motivate the various models that follow, ask yourself why might one expect to find pure wage dispersion? One answer is that search frictions produce a natural trade-off for firms: while posting a higher wage results in lower profit per worker, it potentially could get you more workers. In the Diamond model this trade-off is non-existent, since in equilibrium if you increase your wage above $w_{R}$ there is no increase in the rate at which you hire, given all workers use the same reservation wage. The Albrecht-Axel (1984) model allows for heterogeneity in workers and hence in reservation wages, making the trade-off operational. In particular, assume there are two types of workers, some with $b=b_{1}$ and others with $b=b_{2}>b_{1}$ (one could generalize to $N$ worker types but the point can be made with $N=2$ ).

Now for any wage distribution $F$, there are two reservation wages, $w_{1}$ and $w_{2}>w_{1}$. The generalization of Diamond is that no firm posts a wage other than $w_{1}$ or $w_{2}$, but it seems possible that these two wages could yield equal profit, since low-wage firms hire only workers with $b=b_{1}$ while highwage firms hire everyone. Albrecht-Axel show that wage dispersion is the equilibrium outcome for a large set of parameter values. ${ }^{38}$ To see how this

\footnotetext{
${ }^{37}$ In addition to the models presented below, contributions to the wage or price distribution literature include Butters (1977), Reinganum (1979), MacMinn (1980), Burdett-Judd (1983), Robb (1985) and Diamond (1987).

${ }^{38}$ Several details deserve mention. First, Albrect-Axel do not actually have firms earning equal profit, but allow $p$ to vary and look for a cutoff $p^{*}$ such that firms with $p<p^{*}$ pay $w=w_{1}$ and those with $p>p^{*}$ pay $w=w_{2}$. Also, in some of the models in this section we assume firms care only about steady state profit, which is reasonable when $r \approx 0$. Also,
} 
works, normalize the measure of firms to 1 , and let the measure of workers be $L=L_{1}+L_{2}$ where $L_{j}$ is the measure with $b_{j}$. As we said, all type 1 workers have reservation wage $w_{1}$, all type 2 have $w_{2}>w_{1}$, and in equilibrium all firms post either $w_{1}$ or $w_{2}$. Let $\sigma$ be the endogenous fraction of firms posting $w_{2}$. Any candidate equilibrium wage distribution is completely summarized by $w_{1}, w_{2}$ and $\sigma$.

It should be easy to see that the highest wage posted is $w_{2}=b_{2}$. To determine $w_{1}$, note that type 1 workers accept both $w=w_{1}$ and $w=w_{2}$, and so their value functions satisfy:

$$
\begin{aligned}
r U_{1} & =b_{1}+\alpha \sigma\left[W_{1}\left(w_{2}\right)-U_{1}\right] \\
r W_{1}\left(w_{1}\right) & =w_{1} \\
r W_{1}\left(w_{2}\right) & =w_{2}+\lambda\left[U_{1}-W_{1}\left(w_{2}\right)\right]
\end{aligned}
$$

Note that although $b_{1}$ workers accept $w=w_{1}$, they get no capital gain from doing so and suffer no capital loss when laid off from $w_{1}$. Using $W_{1}\left(w_{1}\right)=U_{1}$ and $w_{2}=b_{2}$, we obtain an equation relating $w_{1}$ to $\sigma$,

$$
w_{1}=\frac{(r+\lambda) b_{1}+\alpha \sigma b_{2}}{r+\lambda+\alpha \sigma} .
$$

The unemployment rates for the two types are $u_{1}=\frac{\lambda}{\alpha+\lambda}$ and $u_{2}=\frac{\lambda}{\alpha \sigma+\lambda}$, and the employment rates are $e_{1}=1-u_{1}$ and $e_{2}=1-u_{2}$. For firms, the expected value of contacting a worker is the product of the probability he accepts and the profit if he accepts. The acceptance probability is $\frac{L_{1} u_{1}}{L_{1} u_{1}+L_{2} u_{2}}$ for firms paying $w_{1}$ and 1 for firms paying $w_{2}$, while discounted profit is $\frac{p-w_{i}}{r+\lambda}$. Therefore,

$$
\begin{aligned}
V_{1} & =\frac{\frac{\lambda}{\alpha+\lambda} L_{1}}{\frac{\lambda}{\alpha+\lambda} L_{1}+\frac{\lambda}{\alpha \sigma+\lambda} L_{2}} \frac{p-\frac{(r+\lambda) b_{1}+\alpha \sigma b_{2}}{r+\lambda+\alpha \sigma}}{r+\lambda} \\
V_{2} & =\frac{p-b_{2}}{r+\lambda} .
\end{aligned}
$$

Algebra reveals that the profit difference $V_{2}-V_{1}$ is proportional to

$$
\begin{aligned}
T(\sigma)= & (r+\lambda+\alpha \sigma)\left\{\left(p-b_{2}\right)\left[\lambda L_{1}+(\alpha+\lambda) L_{2}\right]-\left(p-b_{1}\right) \lambda L_{1}\right\} \\
& -r \alpha \sigma L_{1}\left(b_{2}-b_{1}\right) .
\end{aligned}
$$

instead of random matching, one could alternatively assume you are more likely to meet large firms (Burdett-Vishnawath 1988b; Robin-Roux 1998). Finally, we simply assume firms can commit to $w$ even though they may have incentive ex post to change; Coles (2001) supports this by reputational considerations. 
Hence $\sigma=0$ is an equilibrium if $T(0)<0 ; \sigma=1$ is an equilibrium if $T(1)>0$; and $\sigma \in(0,1)$ is an equilibrium if $T(\sigma)=0$. It is easy to show there exists a unique equilibrium, and $0<\sigma<1$ iff $\underline{p}<p<\bar{p}$ where

$$
\underline{p}=b_{2}+\frac{\lambda L_{1}\left(b_{2}-b_{1}\right)}{(\alpha+\lambda) L_{2}} \text { and } \bar{p}=\underline{p}+\frac{r \alpha L_{1}\left(b_{2}-b_{1}\right)}{(r+\alpha+\lambda)(\alpha+\lambda) L_{2}} \text {. }
$$

When productivity is low all firms pay $w_{1}=b_{1}$, when it is high all firms pay $w_{2}=b_{2}$, and when it is intermediate there is wage dispersion. When $\sigma \in(0,1)$, we can solve $T(\sigma)=0$ for $\sigma$ and use (71) to derive $w_{1}$ explicitly, and the distribution of wages across employed workers is constructed by noting that $e_{j}=1-u_{j}$ workers earn $w_{j}$. Note that $\sigma$ will be less than $e_{2}$ (the fractions of firms posting $w_{2}$ is less than the fraction of workers earning $w_{2}$ ) since high wage firms succeed in hiring more workers. Of course, it is precisely this fact that equates $V_{1}$ and $V_{2}$.

\subsection{A Shirking/Crime Model}

In the Albrecht-Axel model firms may pay higher wages in order to recruit at a faster rate. An alternative idea is that they may pay higher wages to retain workers. Here we present one such model, which can either be interpreted in terms of shirking or crime, since regardless of the interpretation the outcome is similar. ${ }^{39}$ Thus, any employed worker randomly comes across an opportunity to shirk or engage in crime at rate $\mu$, with gross reward $K$. However, there is a probability $\nu$ of getting caught and being forced into unemployment - more generally, in crime models when a worker is caught he can be put in jail for a while, but for simplicity here we assume jail time is zero since what matters for the purpose of generating wage dispersion is simply that the match ends. ${ }^{40}$

To show how things differ from Albrecht-Axel, assume that workers are homogeneous. This implies that there is a common reservation wage $w_{R}$, and

\footnotetext{
${ }^{39}$ See Shapiro-Stiglitz (1984) or Weiss (1980) for efficiency-wage models with shirking, and Burdett-Lagos-Wright (2003, 2004) or Huang-Laing-Wang (2004) for search-based models of crime. The presentation here follows Burdett-Lagos-Wright (2003).

${ }^{40}$ One reason that jail is interesting in the model is the following. In basic efficiency wage models, the firm is supposed to punish a worker caught shirking by laying him off, but this is not really in the firm's interest: what is the point of getting rid of a worker only to search for another who will behave the same? If the police take him away, however, the issue does not come up (i.e., third party enforcement helps on this dimension).
} 
firms can hire any worker they contact by posting $w_{R}$. However, a plausible alternative is to pay something above $w_{R}$ to induce a worker to refrain from the activity in question (shirking or crime). Firms may find this profitable since, after all, they suffer a capital loss when workers leave. To see how it works, let $w_{C}>w_{R}$ denote the critical wage at which a worker would refrain from the activity in question rather than risk losing his job, defined by $K+\nu\left[U-W\left(w_{C}\right)\right]=0$. It is clear that in equilibrium no firm would post anything other than $w_{R}$ or $w_{C}$. As above, let $\sigma$ be the fraction posting the higher wage.

Bellman's equation for a worker are:

$$
\begin{aligned}
r U & =b+\alpha \sigma\left[W\left(w_{C}\right)-U\right] \\
r W\left(w_{R}\right) & =w_{R}+\mu K \\
r W\left(w_{C}\right) & =w_{C}+\lambda\left[U-W\left(w_{C}\right)\right]
\end{aligned}
$$

Although they accept $w_{R}$, they get no capital gain from doing so and suffer no capital loss from losing $w_{R}$. Using $K+\nu\left[U-W\left(w_{C}\right)\right]=0$ and $W\left(w_{R}\right)=U$, we can solve for

$$
\begin{aligned}
& w_{C}=b+(r+\lambda+\alpha \sigma) K / \nu \\
& w_{R}=b-\mu K+\alpha \sigma K / \nu .
\end{aligned}
$$

All firms recruit at the same rate $\alpha L u$, but those paying $w_{R}$ lose workers at rate $\lambda+\mu \nu$ while those paying $w_{C}$ lose workers at rate $\lambda$. Hence,

$$
\begin{aligned}
& V_{R}=\frac{p-w_{R}}{r+\lambda+\mu \nu}=\frac{p-b+\mu K-\alpha \sigma K / \nu}{r+\lambda+\mu \nu} \\
& V_{C}=\frac{p-w_{c}}{r+\lambda}=\frac{p-b-(r+\lambda+\alpha \sigma) K / \nu}{r+\lambda} .
\end{aligned}
$$

Algebra reveals that $V_{C}-V_{R}$ is proportional to

$$
T(\sigma)=\mu \nu(p-b)-(r+\lambda)^{2} K / \nu-\mu(2 r+2 \lambda+\alpha \sigma) K .
$$

As in Albrecht-Axel, there is a unique equilibrium and $0<\sigma<1$ iff $p$ is in some intermediate region. Although the details of the two models are different, the economics is similar: the reason for paying higher wages is that in the end this gets you more workers. 


\subsection{On-the-Job Search}

In the previous two models firms may pay higher wages to either increase the inflow or reduce the outflow of workers. The Burdett-Mortensen (1998) model incorporates both of these ideas by featuring on-the-job search. As in Section 3 , the arrival rates here are $\alpha_{0}$ and $\alpha_{1}$ while unemployed and employed, and every offer is a random draw from $F(w)$. For ease of presentation we begin with the case $\alpha_{0}=\alpha_{1}=\alpha$, which implies $w_{R}=b$ by (19), and return to the general case later. Since all unemployed workers use a common reservation wage, and clearly no firm posts $w<w_{R}$, all jobs are accepted by the unemployed and we have $u=\lambda /(\lambda+\alpha)$.

In this model, the worker inflow for a firm posting $w$ depends upon the distribution of wages across employed workers $G(w)$, since to steal an employed worker you need to beat his current wage. ${ }^{41}$ We now compute $G(w)$, given a distribution of offers $F(w)$. At any $w$, the number of workers employed at a wage no greater than $w$ is $G(w)(1-u)$. This increases over time at rate $\alpha u F(w)$, the rate at which unemployed workers contact a firm paying less than $w$, and decreases over time at rate $\{\lambda+\alpha[1-F(w)] G(w)\}(1-u)$, the rate at which workers employed at less than $w$ are terminated for exogenous reasons plus the rate at which they move to firms paying more than $w$. Equating these flows and inserting $u=\lambda /(\lambda+\alpha)$, we have

$$
G(w)=\frac{\lambda F(w)}{\lambda+\alpha[1-F(w)]} .
$$

If a firm posts $w \geq w_{R}$, a worker he contacts accepts if he is currently unemployed or currently employed but at a lower wage, which occurs with probability $u+(1-u) G(w)$. The employment relationship then yields flow profit $p-w$ until the worker leaves either due to an exogenous separation or a better offer, which occurs at rate $\lambda+\alpha[1-F(w)]$. Therefore, after simplification,

$$
V(w)=\frac{\lambda(p-w)}{\{\lambda+\alpha[1-F(w)]\}\{r+\lambda+\alpha[1-F(w)]\}} .
$$

Again, equilibrium requires that any posted $w$ yields the same profit, which is at least as large as profit from any other wage. Clearly no firm posts

\footnotetext{
${ }^{41}$ The basic model assumes that firms do not respond to outside offers with counteroffers, but this can be relaxed; see Postel-Vinay-Robin (2002).
} 
$w<w_{R}=b$ or $w>p$. In fact, one can show that the support of $F$ is $[b, \bar{w}]$ for some $\bar{w}<p$, and there are neither gaps nor mass points on the support.

We now construct $F$ explicitly. The key step is to use the fact that firms earn equal profits from all posted wages, including the lowest wage $b: V(w)=V(b)$ for every $w \in[b, \bar{w}]$. Since $F(b)=0$, we have $V(b)=$ $\alpha \lambda(p-b) /(\alpha+\lambda)(r+\alpha+\lambda)$. Combining this and (85) gives an equation in $F(w)$ that can be solved for $F(w)$. In the case where $r \approx 0$, the result is

$$
F(w)=\frac{\lambda+\alpha}{\alpha}\left(1-\sqrt{\frac{p-w}{p-b}}\right) .
$$

We know the lower bound is $b$, and the upper bound $\bar{w}$ can easily be found by solving $F(\bar{w})=1$. This yields the unique distribution consistent with equal profit for all wages posted.

In words, the outcome is as follows. All unemployed workers accept the first offer they receive since all firms post $w \geq w_{R}=b$. Then workers move up the wage ladder each time a better offer comes along, but also return to unemployment periodically due to random layoffs. There is a nondegenerate distribution of wages posted by firms, $F$, and of wages earned by workers, $G$. The model has job-to-job transitions and is consistent with several of the other observations about workers that on-the-job search models display. Additionally, it makes predictions about firms, including e.g. the prediction that high wage firms are bigger.

There are many interesting extensions. First, with $\alpha_{0} \neq \alpha_{1}$ the same methods lead to

$$
F(w)=\frac{\lambda+\alpha_{1}}{\alpha_{1}}\left(1-\sqrt{\frac{p-w}{p-w_{R}}}\right),
$$

where now $w_{R}$ is endogenous (with $\alpha_{0}=\alpha_{1}$ we knew $w_{R}=b$ ). To determine $w_{R}$, integrate (19) to get

$$
w_{R}=\frac{\left(\lambda+\alpha_{1}\right)^{2} b+\left(\alpha_{0}-\alpha_{1}\right) \alpha_{1} p}{\left(\lambda+\alpha_{1}\right)^{2}+\left(\alpha_{0}-\alpha_{1}\right) \alpha_{1}} .
$$

One can check that in the limit as $\alpha_{1} \rightarrow 0, \bar{w} \rightarrow w_{R}$, which means there is a single wage, $w=w_{R}=b$; this is the Diamond result as a special case. Also, one can show that in the limit as $\alpha_{1} \rightarrow \infty, \bar{w}=p$ and $G(w)=0$ for all $w<p$; hence all workers earn $w=p$. Moreover, as $\alpha_{0} \rightarrow \infty$, clearly $u \rightarrow 0$. Hence, the competitive solution emerges when $\alpha_{0}$ and $\alpha_{1}$ get large. 
One can also let firms be heterogenous with respect to $p$. In equilibrium there is a distribution of wages paid by each type of firm, and all firms with productivity $p_{2}$ pay more than all firms with $p_{1}<p_{2}$. Thus, higher productivity firms are more likely to hire and less likely to lose any worker. With heterogeneous firms, van den Berg (2003) shows there may be multiple equilibria, while in the base case there is a unique equilibrium (the one we constructed). Perhaps more significantly, firm heterogeneity is an important extension empirically, because with homogeneous firms the equilibrium wage distribution (86) has an increasing density, which is not consistent with the data. With heterogeneity $F$ can have a decreasing density. See Mortensen (2003) for additional discussion and references.

In another generalization, Stevens (2004) allows firms to post wage-tenure contracts, rather than simply a constant $w$. She shows firms have an incentive to back load wages to reduce turnover. If workers can make an up-front payment for a job, an optimal contract extracts an initial fee and then pays $w=p$. If firms are homogeneous this contract eliminates all voluntary quits. In equilibrium all firms demand the same initial fee, and this leaves unemployed workers indifferent about accepting the position. Stevens also shows that if initial payments are impossible, say because of liquidity constraints, there is an equilibrium where all firms offer a contract that pays the worker 0 for a fixed apprenticeship period and then pays $w=p$. Again, if firms are homogeneous they extract all of the surplus, there are no job-to-job transitions, and all contracts are identical.

However Burdett-Coles (2003) show that Stevens's results can be overturned if workers desire smooth consumption. They allow firms to commit to wage-tenure contracts, but assume workers are risk-averse and do not have access to financial markets, and so must consume $w$ each period. They prove all equilibrium wage-tenure contracts are described by a common baseline salary scale, which is an increasing, continuous relationship between $w$ and tenure. Firms offer different contracts in the sense that they start workers at different point on the scale. For instance, a firm might start a worker with an effective tenure of 1 month. Three months later, his effective tenure has increased to 4 months. If he then gets an outside job offer which starts with tenure of less than 4 , he turns it down, but he accepts any more lucrative offer, getting a discrete increase in $w$ when he does. Thus, consumption smoothing reintroduces wage dispersion, both in the sense that workers get different wages depending on their tenure, and in the more fundamental sense that firms offer different contracts. 


\subsection{Other Issues}

We have reviewed three distinct models of wage dispersion, but of course one can combine them - for example, by integrating on-the-job-search into the crime model (Burdett-Lagos-Wright 2004). It is especially important to combine on-the-job search with worker heterogeneity. This is because, although Burdett-Mortensen (with heterogeneous firms) does a good job accounting for wages, it does less well accounting for individual employment histories, especially the fact that hazard rates decrease with the length of the spells. Albrecht-Axel does better at accounting for this, but not so well for wages. Models that combine on-the-job search and worker heterogeneity can potentially account for both (Bontemps-Robin-van den Berg 1999).

It is also possible to add a free-entry condition and thereby endogenize the arrival rate of offers. Mortensen (2000) does this for Burdett-Mortensen; for variety we will do it for Albrecht-Axel. Thus, rather than having a fixed number of firms that meet workers at some constant rate, hiring as many as they can, suppose now that, to attract workers, firms post vacancies, where each vacancy can be filled by at most 1 worker. The rest of the setup is the same as Albrecht-Axel. Thus, any equilibrium wage distribution has a fraction $\sigma$ of vacancies posting $w_{2}=b_{2}$ and the remaining $1-\sigma$ posting $w_{1}$, and we have $u_{1}=\frac{\lambda}{\alpha+\lambda}$ and $u_{2}=\frac{\lambda}{\alpha \sigma+\lambda}$.

We now need to be more careful with the arrival rates. In general one can assume any matching function, but for simplicity consider $m(u, v)=$ $A \min \{u, v\}$. Assume that firms enter, or post vacancies, as long as expected profit exceeds the fixed cost of entry, $k$. Clearly, we will have $v \geq L$ as long as the cost of entry is not too high, since firms make positive profit when $v=L$. Given $v \geq L$ we know $v \geq u$; so the arrival rate for workers is the fixed constant $\alpha=A$, and the arrival rate for firms is $\alpha u / v$. The rate at which a firm meets type $j$ workers is therefore $\frac{\alpha}{v} L_{j} u_{j}$. Let $V_{j}$ and $J_{j}$ be the value functions for a firm given it posts $w_{j}$. Since a firm posting $w_{1}$ hires only type 1 workers,

$$
\begin{aligned}
& r V_{1}=\frac{\alpha}{v} L_{1} u_{1}\left(J_{1}-V_{1}\right) \\
& r J_{1}=p-w_{1}+\lambda\left(J_{1}-V_{1}\right) .
\end{aligned}
$$

The entry condition says that if any firms paying $w_{1}$ enter, we must have $V_{1}=k$. Inserting this and solving we get

$$
r V_{1}=r k=\frac{\alpha}{v} L_{1} u_{1} \frac{p-w_{1}-r k}{r+\lambda} .
$$


Repeating the exercise for any firm posting $w_{2}$, we have

$$
r V_{2}=r k=\frac{\alpha u}{v} \frac{p-w_{2}-r k}{r+\lambda} .
$$

Entry by both types implies $r V_{1}=r k=r V_{2}$, or

$$
T(\sigma)=u\left(p-w_{2}\right)-L_{1} u_{1}\left(p-w_{1}\right)-L_{2} u_{2} r k=0 .
$$

Comparing this with (74), it reduces to exactly the equilibrium condition for our version of the Albrecht-Axel model when $r$ is small.

\section{Efficiency}

An advantage of equilibrium models is that we can discuss welfare. What form do efficient allocations take? Under what conditions are decentralized equilibria efficient? We now turn our attention to these questions. Before we begin, note that in an economy with many agents there can be many Pareto efficient allocations. Here, we focus on those that maximize the sum of agents' utility, or equivalently, that maximize the present discounted value of output, net of the disutility of work and search, and of the cost of posting vacancies.

\subsection{A One-Shot Model}

Initially, $u$ workers are unmatched. Firms decide how many vacancies $v$ to post, each at cost $k$, and then $m(u, v)$ matches form. Let $q=u / v$, and assume constant returns, so $m(u, v)=v m(q, 1)=v \alpha_{e}(q)$. Each match produces $y$ at an opportunity cost $b$ to each worker. Then the economy ends. Firms post vacancies until the free entry condition

$$
\alpha_{e}(q)(1-\theta)(y-b)=k
$$

holds. Assume provisionally that wages are determined by bargaining, $w=$ $\theta y+(1-\theta) b$. This is a static version of the basic Pissarides model.

Now consider a social planner who decides how many vacancies should be posted to maximize output, net of workers' opportunity cost and the cost of posting vacancies. Equivalently, the planner chooses $q=u / v$, knowing that each vacancy will contact a worker with probability $\alpha_{e}(q)$, to maximize

$$
u \alpha_{w}(q)(y-b)-v k=\frac{u}{q}\left[\alpha_{e}(q)(y-b)-k\right] .
$$


The necessary and sufficient condition for a solution is

$$
\left[\alpha_{e}(q)-q \alpha_{e}^{\prime}(q)\right](y-b)=k .
$$

Denote the planner's solution by $q^{*}$.

The following is immediate from (94) and (96): the planner's solution and the decentralized solution coincide iff

$$
\theta^{*}=\varepsilon\left(q^{*}\right),
$$

where $\varepsilon\left(q^{*}\right)=\frac{q^{*} \alpha_{e}^{\prime}\left(q^{*}\right)}{\alpha_{e}\left(q^{*}\right)}$ was defined in Section 5 as the elasticity of $\alpha_{e}(q)$. This is called the Hosios condition (Hosios 1991). It determines the share of the surplus that must go to workers, $\theta^{*}=\varepsilon\left(q^{*}\right)$, for bargaining to be efficient. ${ }^{42}$ Alternatively, in terms of wages, equilibrium is efficient if $w=$ $w^{*}=\theta^{*} y+\left(1-\theta^{*}\right) b$. If $\theta$ is too high, e.g., then $w>w^{*}$ and $v$ is too low.

Now consider competitive search. Recalling (53), in competitive search equilibrium we have $w=w^{*}$, and equilibrium is necessarily efficient. One could say that the Hosios condition holds endogenously (i.e. although there is no bargaining, the surplus is still being split, and the shares are consistent with efficiency). To understand why, it is useful to think of competitive search in terms of competition between market makers, as discussed in Section 5. In an environment with free entry, a market maker in his attempt to earn profit effectively maximizes workers' expected utility, $\alpha_{w}(q)(w-b)$, recognizing that firms must earn zero profits $\alpha_{e}(q)(y-w)=k$ to participate Using the constraint to eliminate $w$ shows that this is identical to the planner's objective function.

Now consider adding search intensity by workers. The total number of matches is $m(\bar{s} u, v)$, where $\bar{s}$ is average intensity. Again assuming constant returns, a firm hires with probability $\alpha_{e}(\bar{s} q)=m(\bar{s} q, 1)$, while a worker with search intensity $s$ gets hired with probability $s \alpha_{w}(\bar{s} q)=s \alpha_{e}(\bar{s} q) / \bar{s} q$. An unemployed worker chooses $s$ to maximize

$$
b-g(s)+\frac{s \alpha_{e}(\bar{s} q) \theta(y-b)}{\bar{s} q} .
$$

In equilibrium all workers choose the same $s=\bar{s}$, where

$$
g^{\prime}(\bar{s})=\frac{\alpha_{e}(\bar{s} q) \theta(y-b)}{\bar{s} q},
$$

\footnotetext{
${ }^{42}$ Because $\alpha_{e}(q)=q \alpha_{w}(q)$, we have $\frac{q \alpha_{e}^{\prime}(q)}{\alpha_{e}(q)}+\frac{q \alpha_{w}^{\prime}(q)}{\alpha_{w}(q)}=1$; hence the condition can equivalently be stated as firms' bargaining power $1-\theta$ must equal the elasticity of $\alpha_{w}(q)$.
} 
and free entry by firms implies

$$
k=\alpha_{e}(\bar{s} q)(1-\theta)(y-b) .
$$

Alternatively, the planner solves

$$
\max _{q, \bar{s}}\left\{b-g(\bar{s})+\frac{\alpha_{e}(\bar{s} q)(y-b)-k}{q} u\right\} .
$$

The necessary and sufficient conditions are

$$
\begin{aligned}
g^{\prime}(\bar{s}) & =\alpha_{e}^{\prime}(\bar{s} q)(y-b) \\
k & =\left[\alpha_{e}(\bar{s} q)-\bar{s} q \alpha_{e}^{\prime}(\bar{s} q)\right](y-b)
\end{aligned}
$$

Notice something interesting: (99) and (102) coincide if the Hosios condition $\theta=\varepsilon(\bar{s} q)$ holds, while (100) and (103) coincide under the same condition. That is, bargaining equilibrium achieves efficient search intensity and entry under the Hosios condition. This seems genuinely surprising, as there are two variables to be determined, $\bar{s}$ and $v$, and 1 free parameter, $\theta$.

Since we have already shown that in competitive search equilibrium we get the Hosios condition endogenously, competitive search equilibrium achieves efficient search intensity and entry. As suggested above, market makers effectively choose the terms of trade to ensure that both workers and firms behave optimally. There is nothing special about endogenous entry decisions or search intensity. We could consider various other extensions (e.g., match-specific productivity with the reservation match value $y_{R}$ determined endogenously), and we would find the same thing: bargaining equilibrium is efficient iff the Hosios condition holds, and competitive search equilibrium generates this condition endogenously. Rather than go through these exercises we now move to dynamics.

\subsection{A Dynamic Model}

Here we formulate the planner's problem for the benchmark Pissarides model recursively. The state variable is the measure of matched workers, or the employment rate, $e$. The current payoff is $y$ for each of the $e$ employed workers, $b$ for each of the $1-e$ unemployed workers, and $-k$ for each of the $v=(1-e) / q$ vacancies. The employment rate follows a law of motion 
$\dot{e}=\frac{\alpha_{e}(q)}{q}(1-e)-\lambda e$. Putting this together, the the planner's problem can be written

$$
r Y(e)=\max _{q}\left\{y e+b(1-e)-\frac{k(1-e)}{q}+Y^{\prime}(e)\left[\frac{\alpha_{e}(q)(1-e)}{q}-\lambda e\right]\right\}
$$

One can easily show that $Y(e)$ is affine; i.e., we have $Y(e)=a_{0}+a_{1} e$ for some constants $a_{0}$ and $a_{1} \cdot{ }^{43}$ These constants have useful interpretations: $a_{0}$ is the value to the planner of an unemployed worker, and $a_{1}$ the added value having a worker matched, or the surplus from a match.

The first order condition from (104) simplifies to

$$
k=a_{1}\left[\alpha_{e}(q)-q \alpha_{e}^{\prime}(q)\right] .
$$

Now use the fact that $Y(e)=a_{0}+a_{1} e$ and the envelope theorem to differentiate both sides of (104):

$$
r a_{1}=y-b+\frac{k}{q}-a_{1}\left[\frac{\alpha_{e}(q)}{q}+\lambda\right]
$$

Combining (105) and (106) to eliminate $a_{1}$, we arrive at

$$
\frac{r+\lambda+\alpha_{e}^{\prime}(q)}{\alpha_{e}(q)-q \alpha_{e}^{\prime}(q)}=\frac{y-b}{k} .
$$

This completely characterizes the optimal policy $q=q(e)$; notice that in fact $q$ does not depend on the state $e$, only on exogenous parameters.

How does this compare with equilibrium? Recall that equilibrium in the bargaining model of Section 4.3 satisfies (39). It is easy to see that the solutions are the same, and hence bargaining equilibrium coincides with the planner's solution, iff the Hosios condition holds, $\theta=\varepsilon(q)$. Now looking at (63) from the competitive search version of the model, we see that competitive search equilibrium is necessarily efficient. Hence the results from the static model generalize directly. Again, for bargaining to be efficient the Hosios condition must hold, since otherwise agents are not getting the share of the surplus that generates efficient behavior, while with competitive search the agents who post the terms of trade internalize this behavior, and an efficient division of the surplus emerges endogenously.

\footnotetext{
${ }^{43}$ The mapping defined by (104) is a contraction and takes affine functions into affine functions. Since the set of such functions is closed, the result follows immediately. This method also works and is especially useful when there is a distribution of productivity across matches.
} 


\subsection{Discussion}

We have demonstrated in several contexts that competitive search is efficient, while bargaining is efficient iff the Hosios condition holds. Although these results are in some sense general, it would be misleading to suggest that we can get efficient equilibria in all search models. A very general understanding of the nature of efficiency in these models is still being developed. MortensenWright (2002) discuss some results for related models, but only for constant returns matching functions; with increasing returns, equilibria are unlikely to be efficient. Also, Shimer-Smith (2001) show that in some models with heterogeneity, even with constant returns, the efficient outcome may not be a steady state but a cycle. ${ }^{44}$

The efficiency of search equilibria with ex ante investments is an interesting topic. For example, in Masters (1998), agents decide on how much capital to acquire prior to searching. ${ }^{45}$ Generically there is no $\theta$ that makes the equilibrium outcome under bargaining efficient - the value of $\theta$ that provides the right incentive for investment in human capital by workers is different from the value of that provides the right incentive for firms (whether firms choose the number of vacancies, the types of jobs to create, or physical capital). However, Acemoglu-Shimer (1999) show competitive search equilibrium with ex ante investments is efficient. Another case where there is no $\theta$ such that bargaining yields the efficient outcome is discussed by Smith (1999), who assumes firms have concave production functions and hire a large number of workers, but bargain with each one individually. Could competitive search correct this?

One can also ask about the efficiency of the wage-posting models in Section 7. In general, if firms commit to pay the same $w$ no matter the circumstances, it is unlikely to yield efficient outcomes. In the Albrecht-Axel model, e.g., a planner would want all meetings to result in matches, but this does not happen. In the basic Burdett-Mortensen model, on the other hand, efficiency does result because all meetings involving unemployed workers result in matches and other meetings are irrelevant from the planner's perspec-

\footnotetext{
${ }^{44}$ The intuition is simple: when the pool of unmatched agents contains mostly high productivity types, it is efficient for agents to be demanding and hold out for a high productivity partner. However, as the pool becomes depleted, they should lower their standards. By lowering their standards they reduce the fraction of low productivity types in the pool, and we are back to where we started.

${ }^{45}$ See also Acemoglu (1996), Burdett-Smith (2001), Coles-Masters (2000), and LaingPalivos-Wang $(1995,2003)$ for other models with human capital.
} 
tive since productivity is the same. Finally, nontransferable utility models typically deliver equilibria that are inefficient. Are there institutions that correct these inefficiencies? These are examples of interesting open questions in search theory.

\section{Conclusion}

We have reviewed various search-based model of the labor market. In contrast to standard supply-and-demand models, search theory emphasizes the frictions inherent in the exchange process, and this leads to many novel insights. There is no single canonical search model, and we have discussed versions that differ along many dimensions, including wage determination, the meeting process, and so on. The specification that is best suited for a particular application depends on the issues at hand. At the same time, it should be clear that there is a common framework underlying all of these specifications, and there are several phenomena that can be analyzed naturally in all the various models, such as wage dispersion and turnover. We have only scratched the surface. But hopefully, this essay will at least convey the basic ideas in search theory and stimulate additional research.

\section{References}

[1] Acemoglu, Daron, "A Microfoundation For Social Increasing Returns in Human Capital Accumulation," Quarterly Journal of Economics, 1996, 111, 779-804.

[2] Acemoglu, Daron, "Changes in Unemployment and Wage Inequality: An Alternative Theory and Some Evidence," American Economic Review, December 1999, 89, 1259-78.

[3] Acemoglu, Daron, "Good Jobs and Bad Jobs," Journal of Labor Economics, 2001, 19, 1-22.

[4] Acemoglu, Daron and Robert Shimer, "Holdups and Efficiency with Search Frictions," International Economic Review, 1999, 40, 827850 . 
[5] Acemoglu, Daron and Robert Shimer, "Efficient Unemployment Insurance," Journal of Political Economy, 1999,107, 893-928.

[6] Acemoglu, Daron and Robert Shimer, "Productivity Gains from Unemployment Insurance," European Economic Review, 2000, 44, $1195-1224$.

[7] Albrecht, James and Bo Axell, "An Equilibrium Model of Search Unemployment," Journal of Political Economy, 1984, 92, 824-40.

[8] Albrecht, James, Pieter Gautier, Serene Tan, Susan Vroman, "Matching with Multiple Applications Revisited," 2004, forthcoming, Economics Letters.

[9] Albrecht, James, Pieter Gautier, Susan Vroman, "Matching with Multiple Applications," Economics Letters 2003, 78, 67-70.

[10] Albrecht, James and Susan Vroman, "Wage Dispersion in a Job Search Model with Time-Varying Unemployment Benefits," mimeo, Georgetown University, 2000.

[11] Albrecht, James and Susan Vroman, "A Matching Model with Endogenous Skill Requirements," International Economic Review, 2002, 43, 283-305.

[12] Alvarez, Fernando and Marcelo Veracierto, "Labor Market Policies in an Equilibrium Search Model," NBER Macroeconomics Annual, 1998, 265-304.

[13] Andolfatto, David, "Business Cycles and Labor Market Search," American Economic Review, 1996, 86, 112-32.

[14] Barlevy, Gadi, "The Sullying Effects of Recessions," Review of Economic Studies, 2002, 69, 65-96.

[15] Blanchard, Olivier J. and Peter A. Diamond, "The Beveridge Curve," Brookings Papers on Economic Activity, 1989, 1, 1-60.

[16] Blanchard, Olivier J. and Pedro Portugal, "What Hides Behind an Unemployment Rate: Comparing Portuguese and U.S. Labor Markets," American Economic Review, 2001, 91, 187-207. 
[17] Bontemps, Christian, Jean-Marc Robin, and Gerard J. van den Berg, "An Empirical Equilibrium Job Search Model with Search on the Job and Heterogeneous Workers and Firms," International Economic Review, 2000, 40, 1039-74.

[18] Browning, Martin, Thomas Crossley and Eric Smith, "Asset Accumulation and Short Term Employment," mimeo, University of Essex, 1999.

[19] Burdett, Kenneth, "A Theory of Employee Job Search and Quit Rates," American Economic Review, March 1978, 68, 212-20.

[20] Burdett, Kenneth, "A Useful Restriction on the Offer Distribution in Job Search Models," in Proceedings of a Symposium at the Industrial Institute for Economic and Social Research. Stockholm, 1981.

[21] Burdett, Kenneth and Melvyn G. Coles, "Marriage and Class," Quarterly Journal of Economics, 1997, 112, 141-68.

[22] Burdett, Kenneth and Melvyn G. Coles, "Long-Term Partnership Formation: Marriage and Employment," Economic Journal, 1999, 109, 307-34.

[23] Burdett, Kenneth and Melvyn G. Coles, "Transplants and Implants: The Economics of Self-Improvement," International Economic Review, 2001, 42, 597-616.

[24] Burdett, Kenneth and Melvyn G. Coles, "Equilibrium WageTenure Contracts," Econometrica, 2003, 71, 1377-1404.

[25] Burdett, Kenneth, Ryoichi Imai and Randall Wright, "Unstable Relationships," Frontiers of Macroeconomics 2004, 1(1), article 1 .

[26] Burdett, Kenneth and Kenneth L. Judd, "Equilibrium Price Distributions," Econometrica, 1983, 51, 955-70.

[27] Burdett, Kenneth, Ricardo Lagos and Randall Wright, "Crime, Inequality, and Unemployment," American Economic Review, 2003, 93, 1764-1777. 
[28] Burdett, Kenneth, Ricardo Lagos and Randall Wright, "An On-the-job Search Model of Crime, Inequality, and Unemployment," 2004, forthcoming, International Economic Review.

[29] Burdett, Kenneth and Dale T. Mortensen, "Search, Layoffs, and Labor Market Equilibrium," Journal of Political Economy, 1980, 88, $652-72$.

[30] Burdett, Kenneth and Dale T. Mortensen, "Wage Differentials, Employer Size, and Unemployment," International Economic Review, 1998, 39, 257-73.

[31] Burdett, Kenneth and Jan Ondrich, "How Changes in Labor Demand Affect Unemployed Workers," Journal of Labor Economics, 1985, $3,1-10$.

[32] Burdett, Kenneth, Shouyong Shi and Randall Wright, "Pricing and Matching with Frictions," Journal of Political Economy, 2001, 109, 1060-1085.

[33] Burdett, Kenneth and Eric Smith, "The Low Skill Trap," European Economic Review, 2001, 46, 1439-1451

[34] Burdett, Kenneth and Tara Vishwanath, "Declining Reservation Wages and Learning," Review of Economic Studies, 1988a, 5, 655-65.

[35] Burdett, Kenneth and Tara Vishwanath, "Balanced Matching and Labor Market Equilibrium," Journal of Political Economy, 1988b, $96,1048-65$.

[36] Burdett, Kenneth and Randall Wright, "Two-Sided Search with Non-Transferrable Utility," Review of Economic Dynamics, January 1998, 1, 220-45.

[37] Butters, Gerard R., "Equilibrium Distributions of Sales and Advertising Prices," Review of Economic Studies, 1977, 44, 465-91.

[38] Caballero, Ricardo J and Mohamad L. Hammour, "The Cleansing Effect of Recessions," American Economic Review 84:5 (1994), 1350-1368. 
[39] Caballero, Ricardo J and Mohamad L. Hammour, "On the Timing and Efficiency of Creative Destruction," Quarterly Journal of Economics, 1996, 111, 805-52.

[40] Cole, Harold L. and Richard Rogerson, "Can the MortensenPissarides Matching Model Match the Business Cycle Facts?" International Economic Review, 1999, 40, 933-60.

[41] Coles, Melvyn G. "Equilibrium Wage Dispersion, Firm Size and Growth." Review of Economic Dynamics, 2001.

[42] Coles, Melvyn G. and Jan Eeckhout, "Heterogeneity as a Coordination Device," 2000, mimeo.

[43] Coles, Melvyn G. and Jan Eeckhout, "Indeterminacy and Directed Search," Journal of Economic Theory, 2003, 111, 265-276.

[44] Coles, Melvyn G. and Adrian Masters, "Long Term Unemployment and Retraining in a Model of Unlearning by Not Doing," European Economic Review, 2000.

[45] Coles, Melvyn G. and Adrian Masters, "Duration Dependent UI Payments and Equilibrium Unemployment," 2000, forthcoming, Economica.

[46] Coles, Melvyn G. and Eric Smith, "Cross Section Estimation of the Matching Function: Evidence from England and Wales," Economica, 1996, 63, 589-87.

[47] Coles, Melvyn G. and Eric Smith, "Marketplaces and Matching," International Economic Review, 1998, 39, 239-54.

[48] Coles, Melvyn G. and Randall Wright, "A Dynamic Equilibrium Model of Search, Bargaining and Money," Journal of Economic Theory, $1998,78,32-54$.

[49] Cornelius, Tracy, "A Search Model of Marriage and Divorce," Review of Economic Dynamics, 2003, 6, 135-155.

[50] Cornelius, Tracy, "Equilibrium Quits and Layoffs in a Model with On-the-Job Search," mimeo, University of Wales, 2000. 
[51] Costain, James, "UI in a General Equilibrium Model of Job Search and Precautionary Savings." Ph.D Dissertation. University of Chicago, 1997.

[52] Costain, James and Michael Reiter, "Business Cycles, UI, and the Calibration of Matching Models," Universidad Carlos III Mimeo, 2003.

[53] Danforth, John P., "On the Role of Consumption and Decreasing Absolute Risk Aversion in the Theory of Job Search," in Studies in the Economics of Search, S. Lippman and J. McCall (eds.) North-Holland, 1979.

[54] Delacroix, Alain, "Transitions into Unemployment and the Nature of Firing Costs," Review of Economic Dynamics, 2003, 6, 651-671.

[55] Delacroix, Alain, "Firing Costs, Minimum Wage and the Outside Option Principle," mimeo, Purdue University, 1999.

[56] den Haan, Wouter J., Garey Ramey and Joel Watson, "Job Destruction and the Propagation of Shocks," American Economic Review, 2000, 90, 482-98.

[57] Devine, Theresa J. and Nicholas M. Kiefer, Empirical Labor Economics: A Search Approach, Oxford: Oxford University Press, 1991.

[58] Diamond, Peter A., "A Model of Price Adjustment." Journal of Economic Theory, 1971, 3, 156-68.

[59] Diamond, Peter A., "Mobility Costs, Frictional Unemployment, and Efficiency," Journal of Political Economy, 1981, 89, 798-812.

[60] Diamond, Peter A., "Aggregate Demand Management in Search Equilibrium," Journal of Political Economy, 1982a, 90, 881-894.

[61] Diamond, Peter A., "Wage Determination and Efficiency in Search Equilibrium," Review of Economic Studies, 1982b, 49, 217-227.

[62] Diamond, Peter A., "Consumer Differences and Prices in a Search Model," Quarterly Journal of Economics, 1987, 102, 429-436. 
[63] Duffie, Darrell, Nicolae Garleanu, and Lasse Pedersen, "Securities Lending, Shorting, and Pricing," Journal of Financial Economics, 2002, 66, 307-339.

[64] Eeckhout, Jan, "Bilateral Search and Vertical Heterogeneity," International Economic Review, 1999, 40, 869-888.

[65] Flinn, Christopher J., and James J. Heckman, "Are Unemployment and Out of the Labor Force Behaviorally Distinct Labor Force States?," Journal of Labor Economics, 1983, 1, 28-42.

[66] Gale, Douglas, "Limit Theorems for Models with Sequential Bargaining," Journal of Economic Theory, 1987, 43, 20-54.

[67] Gomes, Joao, Jeremy Greenwood and Sergio Rebelo, "Equilibrium Unemployment," Journal of Monetary Economics, 2001, 48, 109-152.

[68] Greenwood, Jeremy, Glenn M. MacDonald and Guang-Jia Zhang, "The Cyclical Behavior of Job Creation and Job Destruction: A Sectoral Model," Economic Theory, 1996, 7, 95-112.

[69] Gronau, Reuben, "Information and Frictional Unemployment," American Economic Review, 1971, 61, 290-301.

[70] Hall, Robert E., "Wage Determination and Employment Fluctuations," mimeo, Hoover Institution, Stanford University, August 2003.

[71] Hall J., Steven A. Lippman and John J. McCall, "Expected Utility Maximizing Job Search," in Studies in the Economics of Search, S. Lippman and J. McCall (eds.) North-Holland, 1979.

[72] Hosios, Arthur J., "On the Efficiency of Matching and Related Models of Search and Unemployment," Review of Economic Studies, 1990, $57,279-98$.

[73] Howitt, Peter, "Business Cycles with Costly Search and Recruiting," Quarterly Journal of Economics, 1988, 103, 147-65.

[74] Howitt, Peter and R. Preston McAfee, "Costly Search and Recruiting," International Economic Review, 1987, 28, 89-107. 
[75] Huang, Chieh-Chieh, Derek Laing, and Ping Wang, "Crime and Poverty:" A Search-Theoretic Approach," International Economic Review, 2004, 45, 905-935.

[76] Hwang, Hae shin, Dale T. Mortensen, and Reed, W. Robert, Hedonic Wages and Labor Market Search, Journal of Labor Economics, $1998,16,815-47$.

[77] Jovanovic, Boyan, "Job Matching and the Theory of Turnover," Journal of Political Economy, 1979a, 87, 972-90.

[78] Jovanovic, Boyan, "Firm-specific Capital and Turnover," Journal of Political Economy, 1979b, 87, 1246-60.

[79] Jovanovic, Boyan, "Selection and the Evolution of Industry," Econometrica, 1982, 50, 649-70.

[80] Jovanovic, Boyan, "Work, Rest, and Search: Unemployment, Turnover, and the Cycle," Journal of Labor Economics, 1987, 5 131148.

[81] Jovanovic, Boyan and Glenn M. MacDonald, "Competitive Diffusion," Journal of Political Economy, 1994, 102, 24-52.

[82] Jovanovic, Boyan and Rafael Rob, "The Growth and Diffusion of Knowledge," Review of Economic Studies, October 1989, 56, 569-82.

[83] Benoit Julien, John Kennes, and Ian King, "Bidding for Labor," Review of Economic Dynamics 2000, 3, 619-649.

[84] Kiyotaki, Nobuhiro and Randall Wright, "A Search-Theoretic Approach to Monetary Economics," American Economic Review, March 1993, 83, 63-77.

[85] Lagos, Ricardo, "An Alternative Approach to Search Frictions," Journal of Political Economy, 2000, 108, 851-73.

[86] Laing, Derek, Theodore Palivos, and Ping Wang, "Learning, Matching, and Growth," Review of Economic Studies, 1995, 62, 115129. 
[87] Laing, Derek, Theodore Palivos, and Ping Wang, "The Economics of New Blood," Journal of Economic Theory, 2003,112, 106-56.

[88] Lenz, Rasmus and Torben Tranaes, "Job Search and Savings: Wealth Effects and Duration Dependence," 2003, forthcoming in Journal of Labor Economics.

[89] Lippman, Steven A. and John J. McCall, "The Economics of Job Search: a Survey," Economic Inquiry, 1976a, 14, 347-68.

[90] Lippman, Steven A. and John J. McCall, "Job Search in a Dynamic Economy," Journal of Economic Theory, 1976b, 12, 365-90.

[91] Lippman, Steven A. and John W. Mamer, "A Simple Search Model with Procyclical Quits," Journal of Economic Dynamics and Control, 1989, 13, 247-53.

[92] Ljungqvist, Lars and Thomas J. Sargent, "The European Unemployment Dilemma," Journal of Political Economy, 1998, 106, 514-50.

[93] Lucas, Robert E., Jr. and Edward C. Prescott, "Equilibrium Search and Unemployment," Journal of Economic Theory, 1974, 7, 188-209.

[94] MacMinn, Richard D., "Search and Market Equilibrium," Journal of Political Economy, 1980, 88, 308-27.

[95] Masters, Adrian M., "Efficiency of Physical and Human Capital Investments a Model of Search and Bargaining," International Economic Review, 1998, 39, 477-494

[96] Masters, Adrian M., "Wage Posting in Two-Sided Search and the Minimum Wage," International Economic Review, 1999, 40, 809-26.

[97] McCall, John J., "Economics of Information and Job Search," Quarterly Journal of Economics, 1970, 84, 113-26.

[98] Merz, Monika, "Search in the Labor Market and the Real Business Cycle," Journal of Monetary Economics, 1995, 36, 269-300. 
[99] Merz, Monika, "Heterogeneous Job-Matches and the Cyclical Behavior of Labor Turnover," Journal of Monetary Economics, 1999, 43, $91-124$.

[100] Millard, Stephen P. and Dale T. Mortensen, "The Unemployment and Welfare Effects of Labour Market Policy: A Comparison of the USA and the UK," in Unemployment Policy: Government Options for the Labour Market. D.J. Snower and G. de la Dehesa, eds. New York: Cambridge University Press, 1997.

[101] Moen, Espen R., "Competitive Search Equilibrium," Journal of Political Economy, 1997, 105, 385-411.

[102] Montgomery, James D., "Equilibrium Wage Dispersion and Interindustry Wage Differentials," Quarterly Journal of Economics 106, 1991, 163-179.

[103] Mortensen, Dale T., "A Theory of Wage and Employment Dynamics," in Microeconomic Foundations of Employment and Inflation Theory, E. S. Phelps, et. al. (eds), New York: W.W. Norton, 1970.

[104] Mortensen, Dale T., "UI and Job Search Decisions," Industrial and Labor Relations Review, 1977, 30, 505-17.

[105] Mortensen, Dale T., "The Matching Process as a Noncooperative Bargaining Game," in The Economics of Information and Uncertainty, ed. John J. McCall, Chicago: University of Chicago Press for the National Bureau of Economic Research, 1982b.

[106] Mortensen, Dale T., "Property Rights and Efficiency in Mating, Racing, and Related Games," American Economic Review, 1982b, 72, 968-979.

[107] Mortensen, Dale T., "Job Search and Labor Market Analysis," in Handbook in Labor Economics, O. Ashenfelter and R. Layard (eds.), Amsterdam: North Holland, 1986.

[108] Mortensen, Dale T., "Matching: Finding a Partner for Life or Otherwise," American Journal of Sociology, 1988, 94, S215-S240. 
[109] Mortensen, Dale T., "The Persistence and Indeterminacy of Unemployment in Search Equilibrium," Scandinavian Journal of Economics, 1989, 91, 347-370.

[110] Mortensen, Dale T., "Equilibrium Unemployment Dynamics," International Economic Review, 1999,40, 889-914.

[111] Mortensen, Dale T., "Equilibrium Unemployment with Wage Posting: Burdett-Mortensen Meets Pissarides," in Panel Data and Structural Labor Market Models, H. Bunzel, B.J. Christianesen, N.M. Keifer, and D.T. Mortensen (eds.), Amsterdam: Elsevier, 2000.

[112] Mortensen, Dale T., Wage Dispersion, Cambridge: Zeuthen Lecture Book Series, 2003.

[113] Mortensen, Dale T., "Equilibrium Unemployment with Wage Posting: Burdett-Mortensen Meets Pissarides," in Panel Data and Structural Labor Market Models, H. Bunzel, B.J. Christianesen, N.M. Keifer, and D.T. Mortensen (eds.), Amsterdam: Elsevier, 2000.

[114] Mortensen, Dale T. and George. R. Neumann, "Choice or Chance? A Structural Interpretation of Individual Labor Market Histories," in Studies in Labor Market Dynamics, G.R. Neumann and W. Westergaard-Neilsen (eds.), Heidelberg: Springer-Verlag, 1984.

[115] Mortensen, Dale T. and Christopher A. Pissarides, "Job Creation and Job Destruction in the Theory of Unemployment," Review of Economic Studies, 1994, 61, 397-415.

[116] Mortensen, Dale T. and Christopher A. Pissarides, "New Developments in Models of Search in the Labor Market," in Handbook in Labor Economics, O. Ashenfelter and D. Card (eds.), Amsterdam: North Holland, 1999a.

[117] Mortensen, Dale T. and Christopher A. Pissarides, "Job Reallocation, Employment Fluctuations, and Unemployment Differences," in M. Woodford and J. Taylor (eds.), Handbook of Macroeconomics, Amsterdam; North Holland, 1999b. 
[118] Mortensen, Dale T. and Christopher A. Pissarides, "Unemployment Responses to 'Skill-Biased' Shocks: The Role of Labour Market Policy," Economic Journal, 1999c, 109, 242-65.

[119] Mortensen, Dale T. and Randall Wright, "Competitive Pricing and Efficiency in Search Equilibrium," International Economics Review, 2002, 43, 1-20.

[120] Nash, John, "The Bargaining Problem," Econometrica, 1950, 18, $155-62$.

[121] Osborne, Martin J. and Ariel Rubinstein, Bargaining and Markets, London: Academic Press, 1990.

[122] Peters, Michael, "Equilibrium with Capacity Constraints and Restricted Mobility," Econometrica, 1984, 52, 1117-1129.

[123] Peters, Michael, "Ex Ante Price Offers in Matching Games: Steady States," Econometrica, 1991, 59, 1425-1454.

[124] Petrongolo, Barbara and Christopher A. Pissarides, "Looking into the Black Box: A Survey of the Matching Function," Journal of Economic Literature, 2001, 38, 390-431.

[125] Pissarides, Christopher A., "Search Intensity, Job Advertising, and Efficiency," Journal of Labor Economics, 1984, 2, 128-143.

[126] Pissarides, Christopher A., "Short-run Equilibrium Dynamics of Unemployment, Vacancies, and Real Wages," American Economic Review, 1985, 75, 676-90.

[127] Pissarides, Christopher A., "Unemployment and Vacancies in Britain," Economic Policy, 1986, 3, 499-559.

[128] Pissarides, Christopher A., "Search Unemployment with On-theJob Search," Review of Economic Studies, 1994, 61, 457-75.

[129] Pissarides, Christopher A., Equilibrium Unemployment Theory, second edition, Cambridge, MA: MIT Press, 2000. 
[130] Postel-Vinay, Fabian and Robin, Jean-Marc, "The Distribution of Earnings in an Equilibrium Search Model with State-Dependent Offers and Counter-Offers ," International Economic Review, 2002, 43, 989-1016.

[131] Pries, Michael J., "Persistence of Employment Fluctuations: A Model of Recurring Job Loss," Review of Economic Studies, 2004,71, 193-215.

[132] Pries, Michael J and Richard Rogerson, "Labor Market Institutions and Hiring Policies," mimeo, University of Pennsylvania, 2000.

[133] Reinganum, Jennifer F., "A Simple Equilibrium Model of Price Dispersion," Journal of Political Economy, 1979, 87, 851-8.

[134] Rob, Rafael, "Equilibrium Price Distributions," Review of Economic Studies, 1985, 52, 487-504.

[135] Robin, Jean-Marc and Sebastien Roux, "Equilibrium Search Decisions with Decreasing Returns to Scale and Hiring Costs: Theory and Estimation," mimeo, 1998.

[136] Rothschild, Michael, "Models of Market Organization with Imperfect Information: A Survey," Journal of Political Economy, 1973, 81, $1283-308$.

[137] Rubinstein, Ariel, "Perfect Equilibrium in Bargaining Model," Econometrica, 1982, 50, 97-109.

[138] Rubinstein, Ariel and Asher Wolinsky, "Equilibrium in a Market with Sequential Bargaining," Econometrica, 1985, 53, 1133-50.

[139] Salop, Steven C., "Wage Differentials in a Dynamic Theory of the Firm," Journal of Economic Theory, 1973, 6, 321-44.

[140] Salop, Steven C., "The Noisy Monopolist: Imperfect Information, Price Dispersion and Price Discrimination," Review of Economic Studies, 1977, 44, 393-406.

[141] Shapiro, Carl and Joseph E. Stiglitz, "Equilibrium Unemployment as a Worker Discipline Device," American Economic Review, 1984, 74, $433-44$. 
[142] Shi, Shouyong, "Money and Prices: A Model of Search and Bargaining," Journal of Economic Theory, 1995, 67, 467-96.

[143] Shi, Shouyong, "Frictional Assignment, Part I: Efficiency," Journal of Economic Theory, 2001, 98, 232-260.

[144] Shi, Shouyong, "A Directed Search Model of Inequality with Heterogeneous Skills and Skill-Biased Technology," Review of Economic Studies, 2002, 69, 467-491.

[145] Shimer, Robert, "Contracts in Frictional Labor Markets," mimeo, MIT, 1995.

[146] Shimer, Robert, "Job Auctions," mimeo, Princeton University, 1999.

[147] Shimer, Robert, "The Assignment of Workers to Jobs in an Economy with Coordination Frictions," mimeo, Univeristy of Chicago, 2003.

[148] Shimer, Robert, "The Cyclical Behavior of Equilibrium Unemployment and Vacancies, 2004, forthcoming American Economic Review.

[149] Shimer, Robert and Lones Smith, "Assortative Matching and Search," Econometrica 68:2 (2000a).

[150] Shimer, Robert and Lones Smith, "Nonstationary Search," Princeton University mimeo, 2001.

[151] Simon, Herbert A. "A Behavioral Model of Rational Choice," Quarterly Journal of Economics, 1955, 69, 99-118.

[152] Smith, Eric, "Search, Concave Production and Optimal Firm Size," Review of Economic Dynamics, 1999, 2, 456-471.

[153] Smith, Eric and Kenneth Burdett, "The Low Skill Trap," European Economic Review, (2003), 46,1439-1451.

[154] Stevens, Margaret, "Wage-Tenure Contracts in a Frictional Labour Market: Firms' Strategies for Recruitment and Retention," Review of Economic Studies, 2004, forthcoming.

[155] Stigler, George, "The Economics of Information," Journal of Political Economy, 1961, 69, 213-225. 
[156] Trejos, Alberto and Randall Wright, "Search, Bargaining, Money and Prices," Journal of Political Economy, 1995, 103, 118-41.

[157] Valdivia, Victor, "Evaluating the Welfare Benefits of UI," mimeo, 1995.

[158] van den Berg, Gerard J., "Multiple Equilibria and Minimum Wages in Labor Markets with Informational Frictions and Heterogeneous Production Technologies," International Economic Review, 2003, 44, 13371357.

[159] Weill, Pierre-Olivier, "Leaning Against the Wind," mimeo, Stanford University, 2003.

[160] Weiss, Andrew, "Job Queues and Layoffs in Labor Markets with Flexible Wages," Journal of Political Economy, 1980, 88, 526-38.

[161] Wilde, Louis L., "An Information-Theoretic Approach to Job Quits," in Studies in the Economics of Search, S.A. Lippman and J.J. McCall (eds.), Amsterdam: North-Holland, 1979.

[162] Wolpin, Ken. I., Empirical Methods for the Study of Labor Force Dynamics, Luxembourg: Harwood Academic Publishers, 1995.

[163] Wright, Randall, "Job Search and Cyclical Unemployment," Journal of Political Economy, 1986, 94, 38-55.

[164] Wright, Randall, "Search, Layoffs, and Reservation Wages," Journal of Labor Economics, 1987, 5, 354-365.

[165] Wright, Randall and Janine Loberg, "Unemployment Insurance, Taxes, and Unemployment," Canadian Journal of Economics, 1987, $20,36-54$. 